\title{
La mujer en el registro funerario campaniforme y su reconocimiento social
}

\author{
Women in the funerary Bell Beaker record and their social recognition
}

\author{
Corina Liesau (*) \\ Concepción Blasco (*) \\ Patricia Ríos (**) \\ Raúl Flores $(* * *)$
}

\section{RESUMEN}

El trabajo analiza las tumbas campaniformes con inhumaciones femeninas de tres yacimientos próximos entre sí localizados en la región de Madrid, destacando su presencia en unos contextos que tradicionalmente se han considerado básicamente masculinos. Se registra también la variabilidad de estos contextos, en sus ajuares y en los rituales de inhumación, sean individuales o colectivos y en posiciones primarias o secundarias. Así mismo, se revisan sus asociaciones a individuos masculinos adultos y /o a infantiles, y se discute la asociación de mujeres en tumbas relevantes con puñales. Aunque la muestra es cuantitativamente insuficiente, la variedad del registro nos permite, al menos, desmontar ciertas afirmaciones que se han venido repitiendo sin ningún apoyo empírico sobre la rotunda superioridad numérica de tumbas campaniformes con inhumaciones masculinas. Pero más allá de la recopilación de estos datos es importante reflexionar sobre el porqué de la menor presencia de mujeres con respecto a los hombres en las manifestaciones funerarias de los grupos campaniformes cuando en las tumbas coetáneas no campaniformes es precisamente la mujer la que suele estar mejor representada.

(*) Dpto. de Prehistoria y Arqueología. Universidad Autónoma de Madrid. Facultad de Filosofía y Letras. C/ Tomás y Valiente 1. 28049 Madrid.

Correos e.: corina.liesau@uam.es; concepcion.blasco@uam.es

$(* *)$ Dpto. de Prehistòria, Facultat Filosofia i Lletres. Edifici B. Universitat Autònoma de Barcelona. 08193 Bellaterra. Barcelona. Correo e.: patricia.rios@uab.cat

$(* * *)$ C/ Ciudad Real 46. 28982 Parla. Madrid.

Correo e.: raulfloresfernandez@gmail.com

Recibido: 27-VI-2014; aceptado: 5-VIII-2014.

\begin{abstract}
The paper analyzes the Bell Beaker graves with female burials from three sites located near one another in the region of Madrid. The study addresses the female presence within contexts that have traditionally been considered mainly male. The variability of their grave goods and burial rituals and their identification in primary and secondary, single or collective inhumations, is also analyzed. Their associations with male adult individuals and/ or children are reviewed, and the social role of women buried with daggers in significant graves is discussed. Although the sample is quantitatively insufficient, its variability at least allows us to refute previons claims about the numerical superiority of male graves that have been made without any empirical support. We conclude with a discussion of why there are fewer women in Bell Beaker tombs than in contemporaneous tombs without Bell Beakers.
\end{abstract}

Palabras clave: Calcolítico; Región de Madrid; Campaniforme; Arqueología de la muerte; Aproximación social y de género.

Key words: Chalcolithic; Madrid region; Bell Beaker; Archaeology of Death; Social and Gender perspective.

\section{INTRODUCCIÓN}

Uno de los episodios de la Prehistoria Reciente de la Península Ibérica que más literatura científica ha generado es el fenómeno campaniforme $y$, en particular, sus enterramientos. Sin embar- 
go, la mayoría de los estudios se han dedicado a los elementos que componen los ajuares, en especial a su singular cerámica decorada, los objetos metálicos y otros elementos ornamentales, siendo extensísima la bibliografía disponible a tal efecto (Riaño et al. 1894; Castillo 1928; Delibes 1977; Harrison 1977; Blasco 1994; Blasco et al. 1998; Garrido 2000; Rojo et al. 2005a). Pero es cierto que "en Arqueología en tanto que Ciencia Social, buscamos el rastro de los sujetos sociales no una inexistente vida propia de los objetos" (Escoriza 2008: 20). En consecuencia, ya en fechas tempranas se hicieron importantes esfuerzos en el estudio de los restos antropológicos donde el interés en los mismos iba dirigido a caracterizar racialmente los grupos campaniformes, poniendo un especial énfasis en la osteometría y morfología craneal (Antón 1897; Deselaers 1917; Gerhardt 1953; Bubner 1976). Ya en su día A. del Castillo (1928: 201, 202) indicó “que había que esperar a que los estudios antropológicos estén más maduros, al ser la Antropología la clave para interpretar esta delicada cuestión”, refiriéndose a si se trataba de un fenómeno de "extensión cultural o movimientos étnicos".

En las últimas décadas, los estudios sobre los restos humanos han avanzado considerablemente en la caracterización de las poblaciones prehistóricas. Los enfoques abarcan campos más específicos y cuestiones menos conflictivas que la búsqueda de "pueblos o razas braquicéfalas campaniformes". Sin embargo, las nuevas líneas de investigación -paleogenética, morfologías dentarias, paleodietas, marcadores de estrés ocupacional, etc.- ofrecen ya datos puntuales, además de alguna que otra discusión, en relación con los diferentes aportes arqueométricos, bioantropológicos o paleopatológicos que permitan definir mejor las características entre las poblaciones de finales del Neolítico y/o Calcolítico y las posibles diferencias que presentan aquellos individuos que adoptan el ritual campaniforme (Grupe et al. 1999; Price et al. 2004; Desideri y Besse 2010, 2012; Lee et al. 2012).

Las numerosas intervenciones arqueológicas en el ámbito madrileño han permitido exhumar nuevas tumbas campaniformes, pero los estudios antropológicos se enfrentan a varios problemas. El primero a destacar es que los trabajos antropológicos publicados siguen siendo escasos y al estar siempre relegados a un segundo plano, se ha dado por hecho que las tumbas más importantes pertenecen a varones destacados sin incidir en los restantes miembros de la comunidad: mujeres, infantiles y el resto de la población masculina.

Un segundo problema que limita la obtención de nuevos datos en las excavaciones recientes son las condiciones desfavorables del terreno. La gran profundidad de algunas tumbas en contacto con el nivel freático, o al contrario, su proximidad a la superficie, alterada frecuentemente por las labores agrícolas, no ofrecen ni la cantidad ni la calidad de contextos requeridos por los nuevos estudios. Los esqueletos suelen estar en un estado tan deplorable que, en ocasiones, ni siquiera los especialistas en Antropología pueden identificar de forma fiable el sexo o la edad de los inhumados. Además los procesos posdeposicionales provocan una pérdida tan sustancial del colágeno en los huesos que su datación o estudio paleogenético, entre otros, resulta inviable.

Otra cuestión de no menor envergadura es la práctica vinculada a este horizonte consistente en la reapertura posterior de algunas tumbas para sustraer tanto los ajuares, como las porciones esqueléticas más representativas de los inhumados. Aunque no se trata de casos aislados en el ámbito madrileño, se ha prestado escasa atención a este aspecto cuyo interés obliga a realizar una lectura tafonómica de los enterramientos in situ y limita considerablemente la interpretación cronológica de contextos alterados o con depósitos secundarios (Clop 2010; Liesau et al. 2014).

Estas circunstancias desfavorables nos alejan de poder disponer de visiones de conjunto de los espacios funerarios con tumbas campaniformes. En consecuencia, tampoco nos permiten relacionarlos con los de otros grupos cuyos enterramientos o no contienen estos ajuares o no se identifican con lo que tradicionalmente se ha definido como "set campaniforme", es decir la triada de vaso, cazuela y cuenco, como "equipo ritual" (Delibes 1977: 90; Harrison 1977: 19; Strahm 2004: 202) para preparación y consumo ritual de ciertas bebidas en algunos casos (Guerra Doce 2006; Rojo Guerra et al. 2006; Delibes y Herrán 2007: 197).

Sin embargo, empieza a haber un estimable número de contextos que aportan nuevos datos para aproximarse a un conocimiento más profundo de estas sociedades, pero somos conscientes de lo difícil que resulta ese acercamiento por la ausencia de datos estadísticamente relevantes. El análisis

Trab. Prehist., 72, N. ${ }^{\circ}$ 1, enero-junio 2015, pp. 105-125, ISSN: 0082-5638

doi: $10.3989 /$ tp. 2015.12146 
comparativo de los equipos materiales domésticos y funerarios hay que complementarlo con estudios más detallados de los contextos y exhaustivos análisis paleoantropológicos. Por ello, uno de los objetivos de nuestros estudios de varios yacimientos madrileños ha sido caracterizar lo que Cohen (2011: 21) definió en su día como la "mitad invisible" de la población, la mujer, cuyo peso en la sociedad campaniforme resulta indispensable valorar dentro del marco general de la Prehistoria. Otro objetivo es discutir la aparente homogeneidad de ajuares en el horizonte campaniforme Ciempozuelos, que a la luz de los recientes descubrimientos, muestran un espectro formal muy amplio en estructuras y contenidos. Esta variabilidad sugiere la necesidad de visibilizar una sociedad plural y sus diferentes formas de liderazgo que hasta la fecha parecía reflejarse solo en los registros funerarios y no en los habitacionales.

\section{LAS MUJERES EN LOS CONTEXTOS FUNERARIOS CAMPANIFORMES: TUMBAS Y ASOCIACIONES}

Se tiene asumido que "a medida que avanzó la complejidad socioeconómica, los hombres comenzaron a ocupar posiciones diferentes y a desarrollar el poder, lo cual quiere decir que comenzaban a desvincularse de los demás miembros de su grupo y a proyectar su deseo hostil también dentro de su propio grupo..." (Hernando 2007: 172). La situación se identifica precisamente con el Horizonte Campaniforme al interpretarse que los ajuares depositados en las principales tumbas individuales están constituidos por objetos de lujo y prestigio. Éstos incluyen adornos de vestimentas "masculinas", como botones o adornos realizados con materias primas exóticas y de alto coste como el oro o el marfil.

No obstante, esta hipótesis ha empezado a ser cuestionada por algunos autores que dudan de que todas las tumbas campaniformes pertenezcan a varones, ya que el tradicional planteamiento para explicar el campaniforme como un fenómeno ligado a enterramientos individuales, primarios, de individuos masculinos no sirve para describirlo (Bueno et al. 2005) en cuyo caso ¿cómo se reconocen entonces los enterramientos de las mujeres y de los hijos de estos personajes? (Kunst 2001: 86)
Resulta indispensable recelar de esta visión teórica del campaniforme que se deriva de "divagaciones ideales" (Castro et al. 2003) y realizar un esfuerzo con trabajos arqueológicos de investigación sobre casos reales y no ficticios que tengan en cuenta una sociedad global (Castro et al. 2006). La única vía directa de la que se dispone es acometer un estudio analítico de los inhumados lo más exhaustivo posible que nos acerque a su identificación sexual y de edad, así como a sus características físicas, al grado de parentesco entre ellos, a su esperanza de vida, dieta o dolencias. Un riguroso estudio de los ajuares puede acercarnos a la posible posición social de los individuos inhumados y a la función de hombres y mujeres en el grupo, pero también es cierto que los ajuares "constituyen un poderoso conjunto de símbolos materiales que aluden a sus relaciones familiares o de alianzas, más que su estatus social" (Thomas 2005: 131).

Sin duda alguna, trabajar en estos objetivos ayudaría a caracterizar mejor a la sociedad campaniforme, cuando en otros ámbitos culturales de nuestra Prehistoria reciente se ha avanzado sustancialmente, gracias al amparo de los estudios de género realizados en las últimas décadas. En ellos se ha comenzado a poner el acento en el papel que la mujer debió jugar en todas las sociedades prehistóricas, tanto por su aportación esencial a la subsistencia del grupo como fuerza de trabajo, como por su papel fundamental en la reproducción, la "transmisión genealógica" (Cámara 2001: 56) y su esencial aportación en el contexto familiar y del cuidado de los hijos (Sánchez 2006; Bueno et al. 2012).

Para abordar el tema del posible papel de la mujer entre los grupos campaniformes hemos tenido en cuenta los datos proporcionados por las tumbas femeninas singulares, en parte sincrónicas, localizadas en tres yacimientos calcolíticos madrileños, donde conviven enterramientos con y sin campaniforme: Camino de las Yeseras (San Fernando de Henares), Humanejos (Parla) y La Magdalena (Alcalá de Henares) (Blasco et al. 2011; Heras et al. 2014) (Fig. 1). En este trabajo se reflexiona sobre los datos aportados por diferentes estudios analíticos con especial incidencia en los resultados de informes antropológicos realizados (Gómez et al. 2011), así como los obtenidos por Trancho y Robledo (2011) sobre las paleodietas para los yacimientos de Camino de 


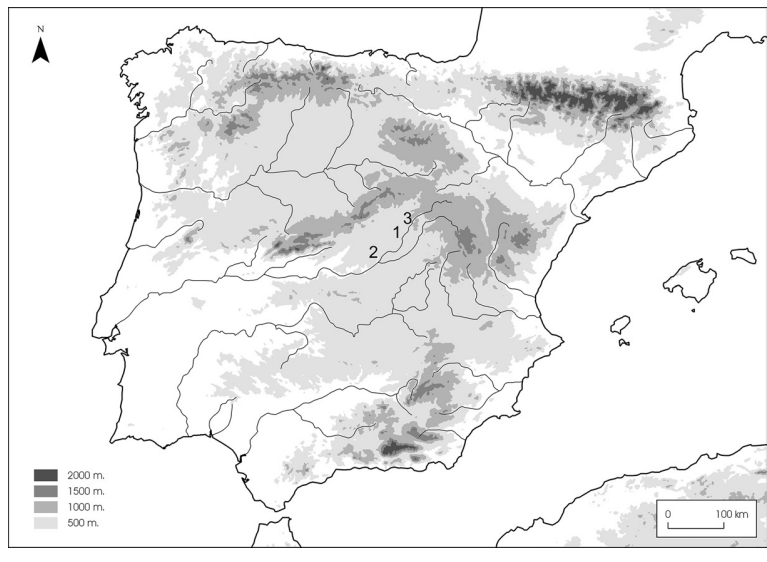

Fig. 1. Localización de los yacimientos analizados en el texto: 1. Camino de las Yeseras (San Fernando de Henares, Madrid), 2. Humanejos (Parla, Madrid) y 3. La Magdalena (Alcalá de Henares, Madrid).

las Yeseras y Humanejos. De La Magdalena se manejan los resultados publicados por Heras et al. (2011 y 2014), que aun siendo preliminares, añaden novedades de interés.

En Camino de las Yeseras se han excavado y estudiado un total de 8 tumbas con ajuares campaniformes, localizadas en 3 áreas funerarias y una doble fosa que han aportado restos correspondientes, al menos, a 19 individuos más otros tantos como depósitos secundarios, actualmente en estudio. En Humanejos se han excavado un total de 6 tumbas de las que se han recuperado restos de 15 individuos (Gómez et al. 2011). A ellas hay que sumar las 4 tumbas campaniformes con un total de 11 inhumaciones procedentes del yacimiento de La Magdalena de las que sólo tenemos datos muy parciales (Heras et al. 2011)

\subsection{Tumbas colectivas 0 múltiples con inhumaciones primarias y/o depósitos secundarios}

Dos de las cuatro tumbas campaniformes de Camino de las Yeseras analizadas donde se han inhumado mujeres son enterramientos dobles de hombre y mujer, un dato que podría indicar que, al menos en algunos casos, su acceso a este grupo podría haberse producido por consanguinidad si bien las observaciones tafonómicas y las aso- ciaciones permiten suponer que pudieron existir otras causas.

Una de las tumbas del Área Funeraria 3 (antes cabaña 5, según Blasco et al. 2005) de Camino de las Yeseras es una covacha/hipogeo (Fig. 2a) con restos de cuatro cuerpos según los últimos informes antropológicos. Estaba abierta en el zócalo de una amplia estructura. En su base quedaron alojados los restos reducidos de dos varones, uno de ellos maduro. Por encima se localizó un esqueleto de mujer en posición primaria, con las piernas flexionadas y orientación E-O. Ella estaba parcialmente infrapuesta a un varón adulto, en decúbito supino con los brazos cruzados orientado en dirección O-E y colocado, por falta de espacio, en la propia entrada de la tumba (Fig. 2b).

Todo parece indicar que, al menos, las dos últimas inhumaciones se produjeron en un espacio corto de tiempo: primero la mujer de 40 años y después un varón de entre 30 y 40 años, cuyos restos han proporcionado una datación de 3650 \pm 40 BP (BETA 184837) que, calibrada a $2 \sigma$, ofrecen un lapso temporal de 2280-2030 cal BC. Ambos individuos poseen ajuares aparentemente modestos, algo más importante el del varón: la mujer se asocia a una cazuela con una escueta decoración campaniforme que cubre sólo la cara exterior de la boca (Fig. 3a), a un vaso liso y a un mortero de arenisca (Fig. 4c), pero el varón posee dos cuencos y un vaso con decoración campaniforme, además de un molino. Se recuperó también un punzón de cobre (Fig. 5e), inicialmente asignado como ajuar al varón (Blasco et al. 2005: 461-462), pero no descartamos que pudiera corresponder a la mujer por la superposición parcial de los cuerpos y por la falta de localización exacta de la pieza.

La modestia de estos ajuares podría ser más aparente que real pues la presencia del mortero y el molino, ambos realizados en arenisca (Blasco et. al 2007-2008:761), en los ajuares de esta pareja, podría estar en relación con la hipótesis de que "la emergencia de élites en los grupos humanos implicó, con frecuencia, la apropiación de parte de la producción relacionada con las actividades de mantenimiento, apropiación que se usó para asentar las bases de la jerarquización social. Se trata de materiales arqueológicos normalmente ligados al ámbito doméstico, como fusayolas, pesas de telar, molinos de mano, etc., [que] empiezan a aparecer en lugares que, por 

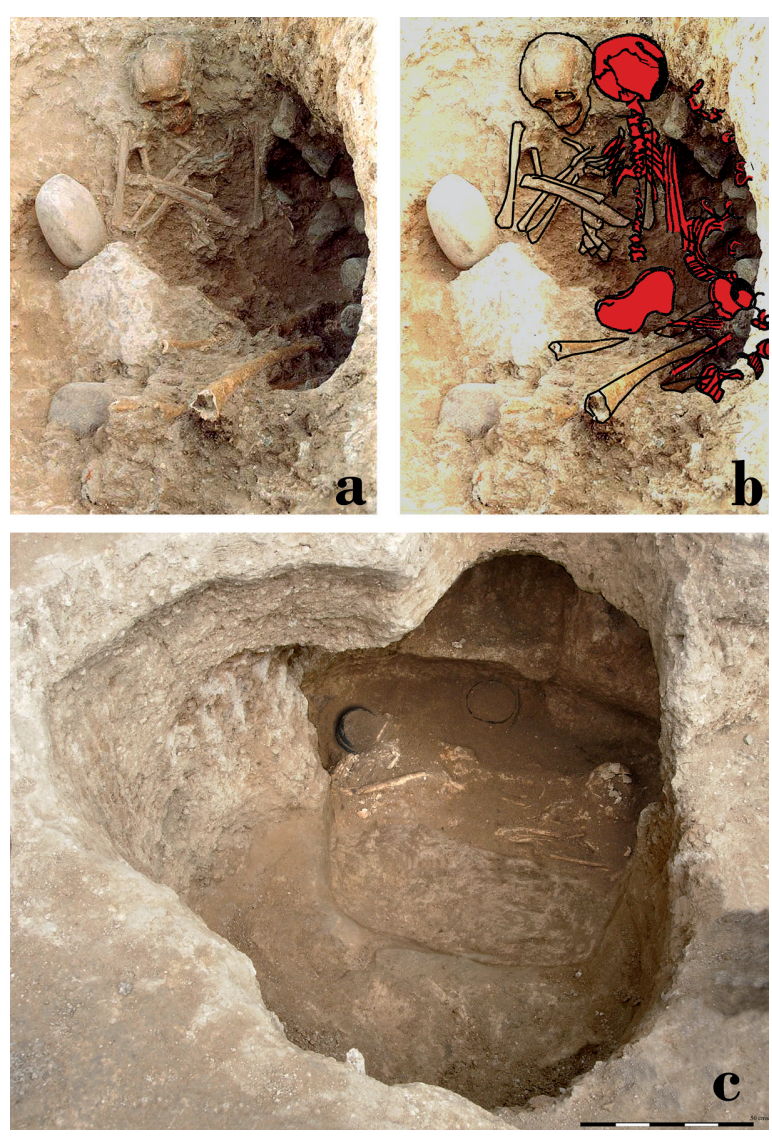

Fig. 2. Camino de las Yeseras (San Fernando de Henares, Madrid). Tumbas colectivas con inhumaciones primarias y/o depósitos secundarios: a y b "Área funeraria 3"; c "Área funeraria 1" (Foto Argea S.L).

su situación o su forma de construcción, están asociados a otras esferas de la acción social, como la política, la religiosa o la del intercambio a escala no local" (González Marcén et al. 2007: 176).

La segunda tumba en covacha (Fig. 2c) con restos de tres individuos se encuentra en el Área Funeraria 1 del mismo yacimiento de Camino de las Yeseras (Liesau et al. 2008; Blasco et al. 2009). En este caso sólo se recuperó, junto a un fragmento de órbita infantil, parte del esqueleto de un varón maduro depositado formando un paquete de varios huesos largos cubriendo el cráneo, todo ello colocado cerca de la entrada de la covacha. La ausencia de gran parte del esqueleto permite deducir que se trata de un depósito secundario. Dicho depósito se produjo junto a la cabeza de un adulto de entre 20-30 años de edad en inhumación primaria en decúbito lateral izquierdo quien entre sus piernas exhibía dos cuencos superpuestos (Fig. 3b) y a su espalda otro (tal vez el ajuar del varón en posición secundaria). Desgraciadamente el estado de conservación del esqueleto era tan deplorable que no ha sido posible sexar esta última inhumación, aunque por la gracilidad del cráneo y del esqueleto postcraneal parece ser una mujer. También el tipo de ajuar podría confirmar esa posibilidad. En tal caso, ¿fue ella la que propició la construcción de esta tumba singular?

\subsection{Enterramientos dobles: varón o adulto y mujer}

Mucho más significativa es la doble inhumación (Fig. 6a) recuperada en Humanejos (Gómez et al. 2011: 117) un varón inhumado en la base de una de una cámara subterránea de planta cuadrangular que debió de estar cubierta por un túmulo de grandes piedras. Estaba acompañado por un espectacular ajuar con alabarda, puñal, dos puntas palmela de cobre y brazal de esquisto. Por el contrario, la mujer (Fig. 6b), inhumada en un nivel superior, sólo tenía asignado punzón de cobre (Fig. 5c) que debió de sostener en la mano. Hay también un importante lote de vasos campaniformes de gran variedad y riqueza ornamental, algunos de gran tamaño y todos ellos con abundantes restos de cinabrio. Esta sustancia fue aplicada también a una parte del cuerpo del varón, pero no al de la mujer. Ello nos permite suponer que esta vajilla o, al menos, una buena parte de ella, hay que adscribirla al ajuar masculino, al que pertenecerían también las cuentas y botones de marfil introducidos en una de las cazuelas, las cuales estaban igualmente impregnadas de cinabrio.

En este caso la primera inhumación fue la del varón y un tiempo después se depositó el cuerpo de la mujer. La diferencia de edad entre ellos es mayor que la documentada en el Área Funeraria 1 de Camino de las Yeseras: él unos 45 años y ella alrededor de 20. La diacronía entre el óbito de ambos parece quedar confirmada por dataciones de AMS y las observaciones tafonómicas que la apoyan. No obstante a pesar de que los resultados del C14 dieron una antigüedad para el varón de 

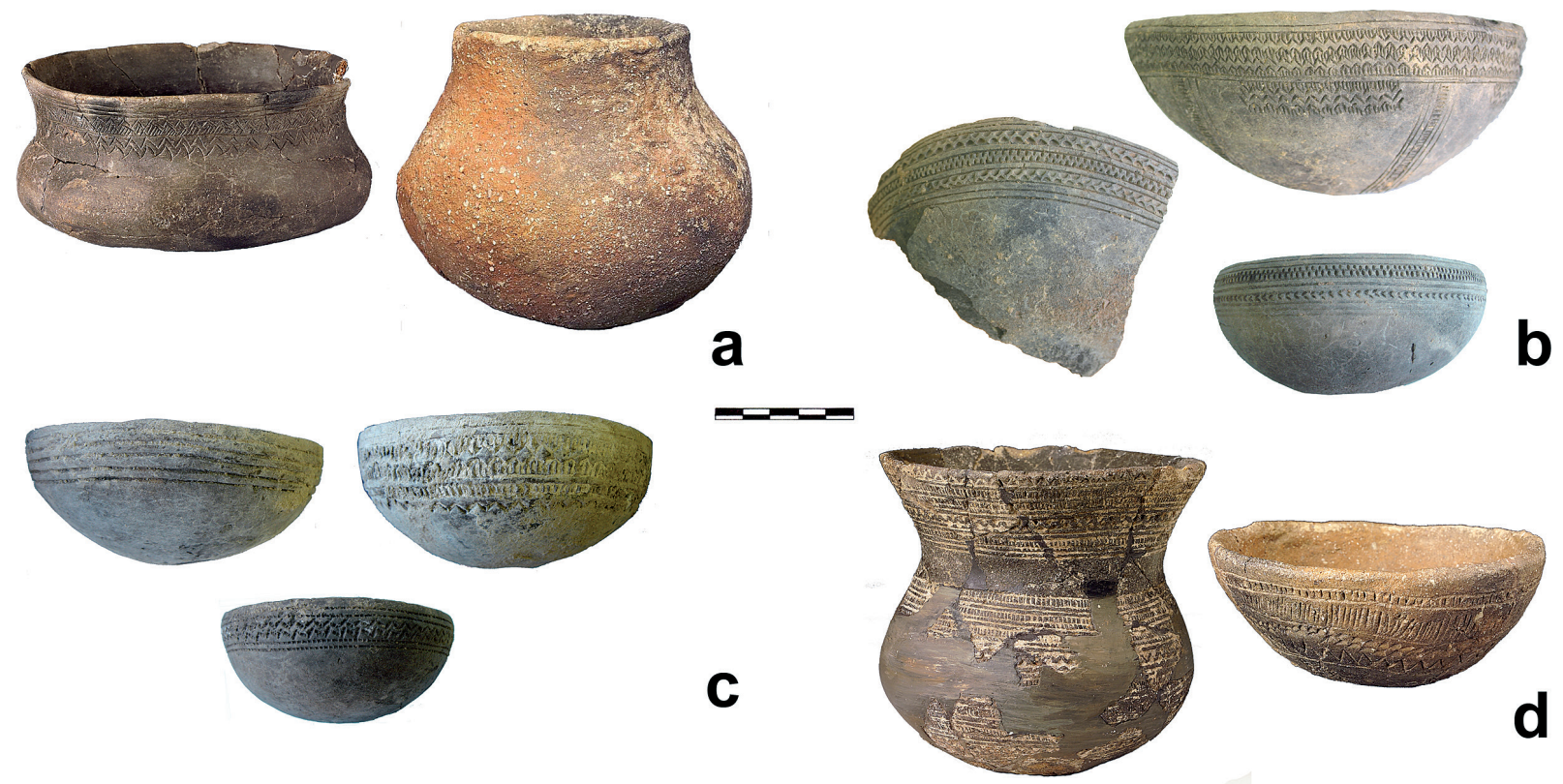

Fig. 3. Recipientes campaniformes de los ajuares femeninos de Camino de las Yeseras: a. Tumba múltiple del "Área funeraria 3"; b. Tumba múltiple del "Área funeraria 1"; c. Tumba doble del "Área funeraria 2"; d. Tumba individual del "Área funeraria 3" (fotografías a. y d. a partir de las de Blasco et al. 2005: figs.10 y 11 realizadas por Mario Torquemada, Museo Arqueológico Regional, Alcalá de Henares).

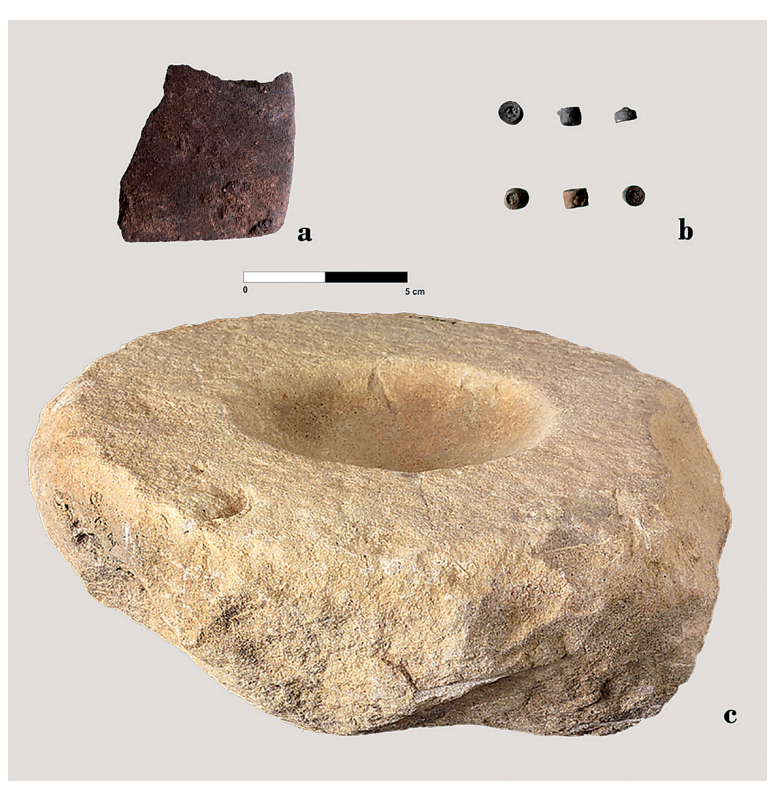

Fig. 4. Material lítico recuperado de las tumbas femeninas estudiadas: a. afilador y b. cuentas de collar verdes de la tumba individual de Humanejos; c. mortero de arenisca del ajuar femenino de la tumba múltiple del "Área funeraria 3" de Camino de las Yeseras.

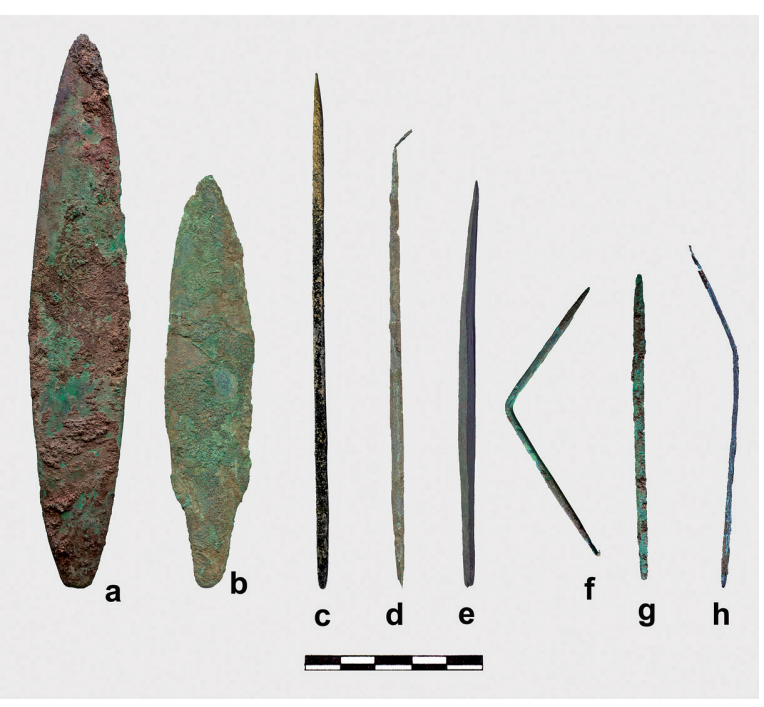

Fig. 5. Ajuares metálicos de las tumbas femeninas estudiadas: a y d. Puñal de lengüeta y punzón respectivamente del ajuar femenino de la tumba múltiple de Humanejos (UE 1166); h. Punzón asociado a uno de los infantiles de la misma tumba; b, f y g. Puñal foliáceo y punzones del ajuar femenino de la tumba individual de Humanejos (UE 1701); c. Punzón asociado a la mujer de la inhumación doble de Humanejos (UE 1853); y e. Punzón que probablemente corresponda al único individuo femenino de la tumba múltiple del "Área funeraria 3" de Camino de las Yeseras. 


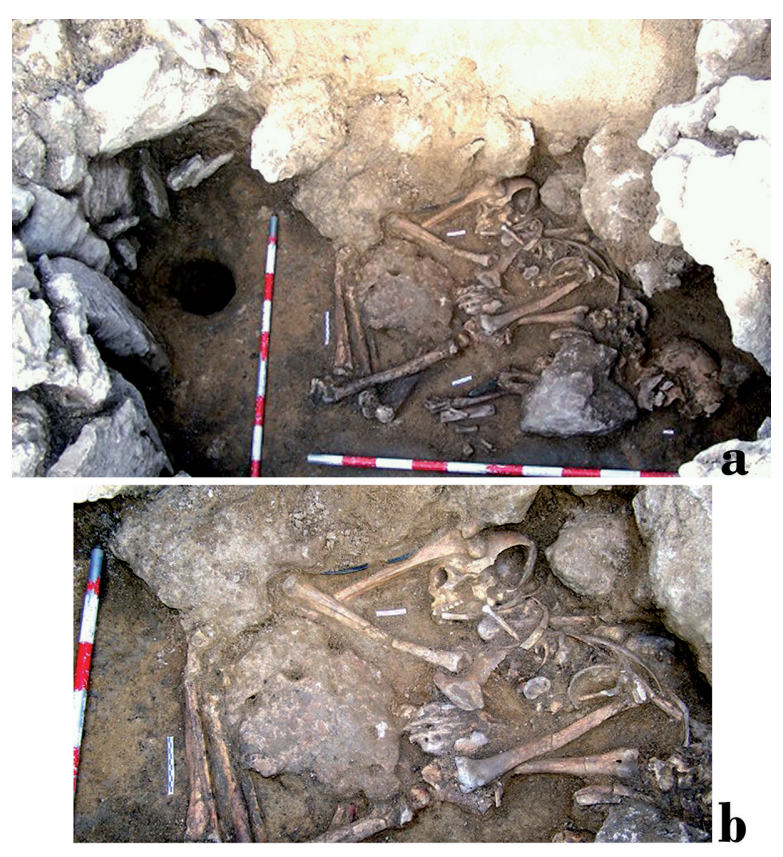

Fig. 6. Enterramientos doble de varón (a) y mujer (b) de Humanejos (Parla) (UE 1853).

$3917 \pm 33$ BP (Ua 43524) y de $3797 \pm 32$ BP (Ua 43525) para la mujer, la calibración a $2 \sigma$ apunta a un lapso temporal de entre 2490-2290 cal BC y 2230-2130 cal BC respectivamente, lo que indica que el fallecimiento de ambos pudo estar próximo en el tiempo

Por otra parte, con el fin de mantener al varón en su posición original en el centro de la tumba, la mujer se dispuso en parte por encima de él evidenciando tal vez una supeditación en la colocación del cuerpo femenino en un lateral con respecto al sujeto principal del enterramiento. El hecho de ser introducidos en la misma tumba parece indicar una relación directa, ¿fue un vínculo de consanguinidad?

La precaria conservación de los esqueletos femeninos en las tres tumbas comentadas nos ha impedido extraer datos concluyentes sobre la calidad de vida de estas mujeres, a excepción de una antigua fractura de clavícula de la mujer de Humanejos. Tampoco se ha podido comprobar que existiera una muerte violenta. Sea como sea, si en el primer caso se confirmara que se trata de una mujer, evidencia que fue merecedora de una tumba singular. En los otros contextos su papel parece limitarse al de acompañante del personaje principal, si aceptamos que un ajuar rico y/o singular es un indicio de prestigio que se asigna a un líder (Andrés 2005: 181, 2012: 33). En la tumba doble de Humanejos, el ajuar suma a una significativa panoplia, un espectacular lote de vajilla y materiales exóticos como marfil y cinabrio.

\subsection{Enterramientos dobles: ¿dos mujeres adultas?}

En este apartado hay que incluir una de las tumbas de La Magdalena con dos fases de inhumación en bien diferenciados. El primero de ellos se documentada en la base de la fosa está representado por restos muy parciales e inconexos pertenecientes individuo adulto femenino en clara posición secundaria, bien por una remoción de la tumba, bien por su traslado desde otro lugar. Estaba asociado a dos recipientes: un vaso de estilo Ciempozuelos y una "olla de almacenamiento lisa" (Heras et al. 2011: 19-20; Heras et al. 2014: 217). Este conjunto fue sellado por un nivel de relleno con una potencia de alrededor de $1 \mathrm{~m}$. Pero lo más extraordinario de esta fosa resulta la presencia, sobre el conjunto descrito y a una profundidad de unos $0,76 \mathrm{~m}$, de otras dos mujeres, una senil y otra adulta joven, sin ajuar, con las piernas flexionadas $\mathrm{y}$

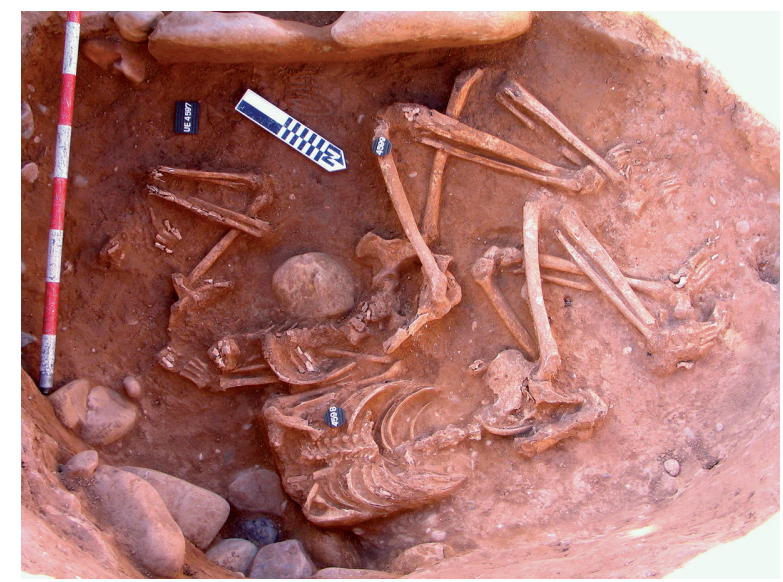

Fig. 7. Inhumaciones femeninas a falta del cráneo y de las primeras vértebras depositadas en el nivel superior del "falso hipogeo de La Magdalena" (Alcalá de Henares) (UT 4600) (foto César Heras). 
con sus cuerpos en paralelo y orientados hacia el Sur. Ambos esqueletos presentan la misma singularidad: les falta el cráneo y las primeras vértebras cervicales (C1-C4) (Heras et al. 2011: 19) (Fig. 7).

La ausencia de dataciones nos impide determinar el tiempo transcurrido entre ambos depósitos y si el segundo se practicó cuando se produjo la remoción o el traslado de los restos del nivel inferior. Además, no ha sido posible comprobar si las mujeres fueron decapitadas o la retirada de los cráneos fue postdeposicional, una vez esqueletizados sus cuerpos.

\subsection{Enterramiento doble: mujer e infantil}

El Área Funeraria 2 de Camino de las Yeseras muestra una fórmula diferente. Aquí la inhumación femenina se practicó en una covacha abierta en el zócalo de una estructura, de tendencia circular y unos $60 \mathrm{~m}^{2}$ (Liesau et al. 2008: 113; Blasco et al. 2009: 58-59). La mujer yacía en decúbito lateral izquierdo, en posición contraída (Fig. 8a), mirando hacia el interior de la estructura funeraria y bajo sus pies se localizó un niño cercano al año, datado en $3525 \pm 40 \mathrm{BP}$ (Ua 35021) con una calibración a $2 \sigma$ de 1960-1740 cal BC. El ajuar de ambos consiste en tres cuencos campaniformes
(Fig. 3c) con decoraciones similares. Se colocaron el más pequeño bocabajo junto al infantil y los otros dos superpuestos entre el brazo y el costado izquierdo de la mujer.

En el mismo recinto funerario se excavaron otras dos tumbas: una segunda covacha y un hipogeo. En la primera se inhumó un varón adulto $\mathrm{y}$ en el segundo se depositó un varón joven embadurnado con cinabrio, acompañado por una extraordinaria cazuela de estilo Ciempozuelos con una decoración simbólica de ciervos y posiblemente ciervas o machos con el asta mudada. Además se recuperaron numerosos ornamentos, uno de ellos un posible tocado realizado con una veintena de cuentas de oro y dos placas del mismo material, al que se suman un posible collar de cuentas de marfil y tres botones con perforación en $\mathrm{V}$, también de marfil (Blasco et al. 2009; Blasco y Ríos 2010; Liesau y Moreno 2012).

Parece lógico pensar que la mujer estuviera emparentada o íntimamente relacionada con los individuos enterrados en la misma estructura funeraria a modo de panteón familiar aunque no compartiera tumba con ellos. Por otra parte, resulta relevante la deformación craneal piriforme de la mujer, causada en la infancia y producida por haber tenido fuertemente presionada su cabeza con vendas o tablillas. El efecto visual y distintivo de aquella modificación intencional la
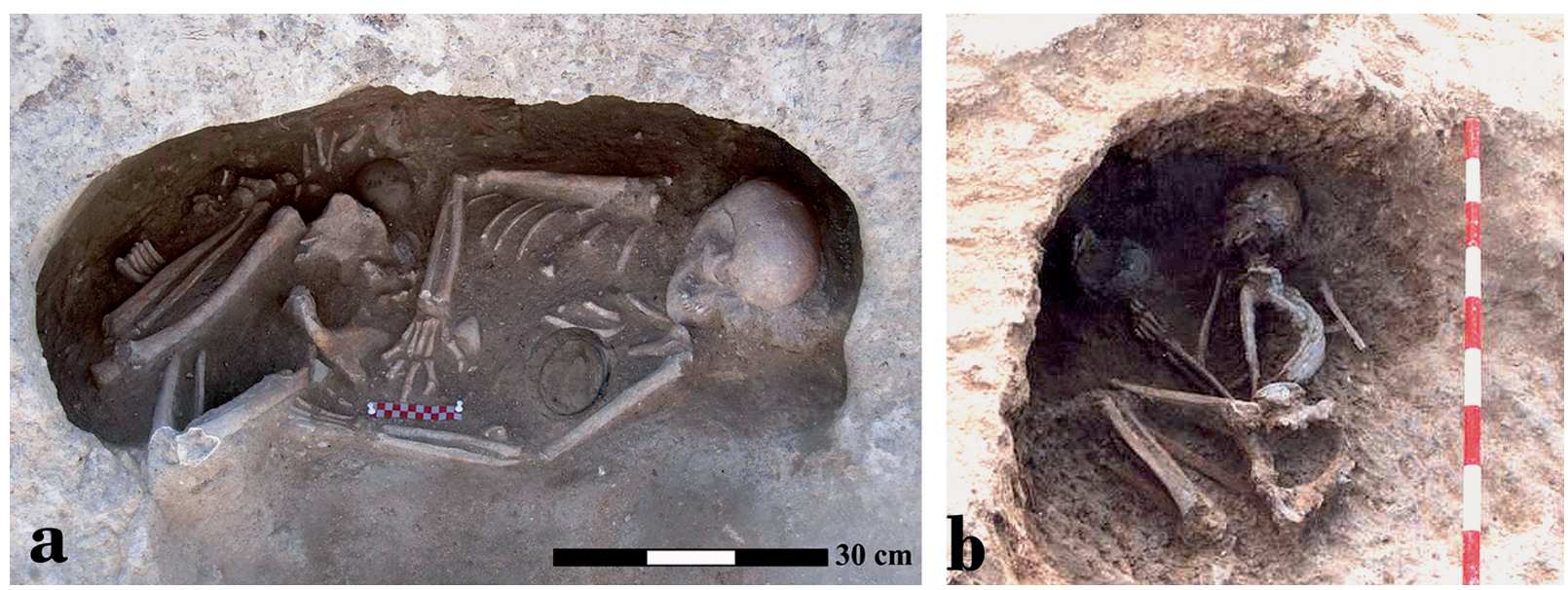

Fig. 8. Camino de las Yeseras (San Fernando de Henares): a. enterramiento doble en covacha: de mujer e infantil del "Area funeraria 2" (Foto: Argea S.L.); b. enterramiento individual en covacha de mujer "Área funeraria 3" (Foto a partir de Blasco et al. 2005: Fig. 7).

Trab. Prehist., 72, N. ${ }^{\circ}$ 1, enero-junio 2015, pp. 105-125, ISSN: 0082-5638

doi: $10.3989 /$ tp.2015.12146 
hacía, sin duda alguna, diferente a otras mujeres. La excepcionalidad de este caso, junto con la ausencia de fuertes inserciones musculares en los brazos que están reiteradamente presentes en las mujeres sin ajuar campaniforme parecen ser suficientes indicios para suponer que su condición social le pudo proporcionar una calidad de vida exenta de las duras tareas realizadas habitualmente por buena parte de las mujeres sin campaniforme coetáneas del mismo asentamiento.

\subsection{Enterramiento individual de mujer}

En Camino de las Yeseras, tan sólo se ha documentado una tumba individual femenina en covacha con ajuar campaniforme localizada en el Área Funeraria 3 (denominada "Cabaña 5" en Blasco et al. 2005) (Fig. 8b). El cuerpo de la mujer se encontraba en la habitual posición contraída en decúbito lateral derecho, y asociada a un modesto ajuar compuesto por una cazuela y un vaso con una escueta e incluso desmañada ornamentación campaniforme (Fig. 3d). Al encontrarse el enterramiento en la exposición permanente del Museo Arqueológico Regional de Madrid no ha sido posible obtener una muestra para su datación.

Desconocemos cual pudo ser la relación de esta mujer con los personajes de la inhumación colectiva a la que nos hemos referido en el apartado 2.1, pero no pasa desapercibido el que ambas tumbas estuvieran prácticamente adyacentes, dejando libre el resto de la amplia estructura en cuyos zócalos fueron excavadas. Cabe destacar que se trata de una adulta de entre 20 y 30 años. $\mathrm{Su}$ ajuar no es extraordinario, ni por la calidad de los recipientes, ni por su estilo decorativo, pero el hecho de haber sido inhumada de forma individual y que sostenga entre sus brazos o manos un vaso, es un detalle que suele ser habitual en las posturas deposicionales masculinas, como la del varón adulto de la covacha del Área Funeraria 2 o la de un individuo de Ciempozuelos, cuyo sexo evidentemente se desconoce. Los restos óseos de una de sus manos permanecían adheridos a la base de una de las cazuelas incisas e impresas (Riaño et al. 1894: lám. 4; Castillo 1928: lám. XVIII,1).

\subsection{Mujeres sin vajilla campaniforme pero con su metalurgia distintiva}

Existen dos tumbas femeninas del yacimiento de Humanejos que resultan excepcionales por poseer los ajuares más destacados de entre las féminas, aún sin incluir la característica vajilla campaniforme (Fig. 9). Ambas fueron sometidas a un ritual propio de los grupos campaniformes, como es la colocación de los cuerpos en decúbito lateral con las piernas flexionadas y la inclusión de elementos y materias primas reservadas a sus líderes: posibles mortajas con prendas impregnadas de cinabrio y/o espolvoreado de los cuerpos con este colorante además de portar ornatos elaborados con piedras verdes que en necrópolis campaniformes próximas, como la del valle de las Higueras están asociadas con vajilla campaniforme (Bueno et al. 2005: 74, 2012). Lo más interesante es que con ellas se amortizaron objetos
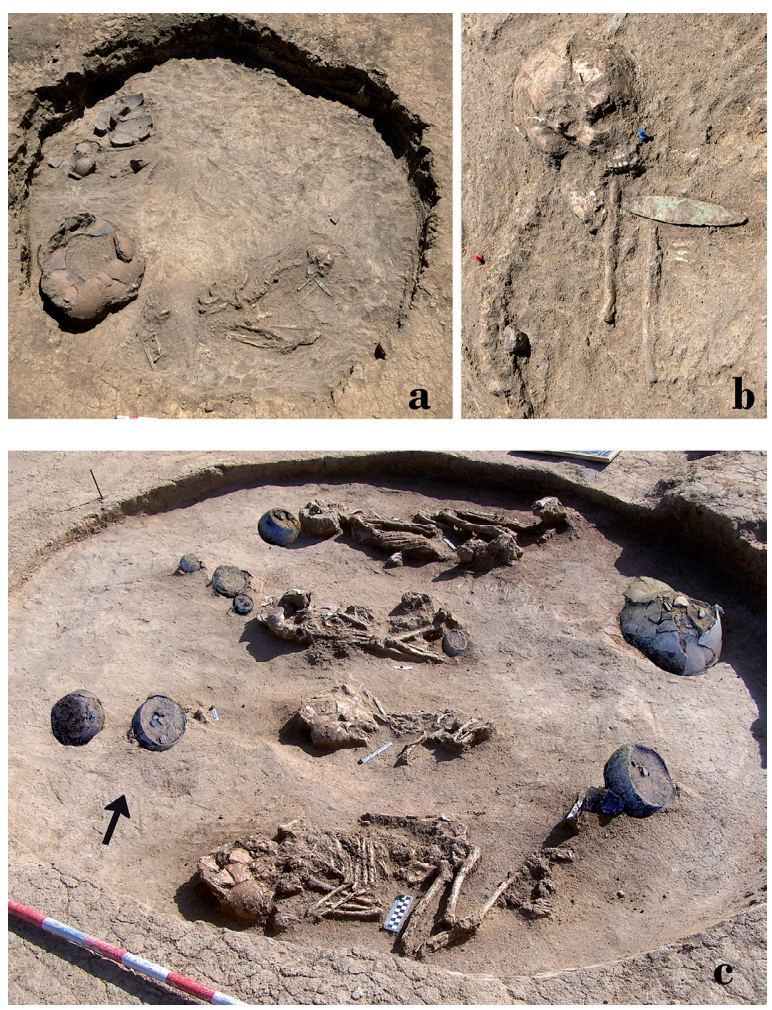

Fig. 9. Humanejos (Parla). Tumbas femeninas que incorporan armas en el ajuar: a. inhumación individual, b. detalle (UE 1701); c. inhumación femenina con tres infantiles (UE 1166). 


\begin{tabular}{|c|c|c|c|c|c|}
\hline $\begin{array}{l}\text { Tumbas con } \\
\text { campaniforme } \\
\text { o elementos } \\
\text { asociados al } \\
\text { campaniforme }\end{array}$ & Mujeres & $\begin{array}{l}\text { 1. Decúbito lateral } \\
\text { 2. Orientación y cara } \\
\text { mirando hacia... } \\
\text { 3. Posición de las piernas }\end{array}$ & Hombres & Infantiles & $\begin{array}{c}\text { Ajuares } \\
\text { femeninos }\end{array}$ \\
\hline $\begin{array}{l}\text { C. Yeseras: } \\
\text { A. Funeraria } 1 \\
\text { (A31, EO1, II) }\end{array}$ & 1 (20-30 años) & $\begin{array}{l}\text { 1. izquierdo } \\
\text { 2. S-N, cara al O } \\
\text { 3. flexión laxa }\end{array}$ & $\begin{array}{l}1 \text { maduro } \\
\text { (secundario) }\end{array}$ & $\begin{array}{c}1 \text { ¿secundario/ } \\
\text { intrusivo?) }\end{array}$ & 2 cuencos \\
\hline $\begin{array}{c}\text { C. Yeseras: } \\
\text { A. Funeraria } 2 \\
(\mathrm{~A} 36, \mathrm{EO} 3, \mathrm{VII})\end{array}$ & 1 (20-30 años) & $\begin{array}{l}\text { 1. izquierdo } \\
\text { 2. N-S, cara al E } \\
\text { 3. flexión contraída }\end{array}$ & & 1 ( \pm 1 año) & 2 cuencos \\
\hline $\begin{array}{l}\text { C. Yeseras: } \\
\text { A. Funeraria } 3 \\
\quad(\mathrm{~F}-5-\mathrm{I})\end{array}$ & $\begin{array}{c}1 \text { mujer } \\
\text { (20-30 años) }\end{array}$ & $\begin{array}{l}\text { 1. derecho } \\
\text { 2. S-N, cara al E } \\
\text { 3. flexión laxa }\end{array}$ & & & $\begin{array}{c}1 \text { vaso } \\
1 \text { cuenco }\end{array}$ \\
\hline $\begin{array}{l}\text { C. Yeseras: } \\
\text { A. Funeraria } 3 \\
\quad(\mathrm{~F}-5-\mathrm{II})\end{array}$ & 1 (>40 años) & $\begin{array}{l}\text { 1. ¿izquierdo? } \\
\text { 2. E-O, cara al S } \\
\text { 3. flexión contraída }\end{array}$ & $\begin{array}{l}1 \text { (30-40 años) } \\
1 \text { adulto maduro } \\
\text { (secundario) } \\
1 \text { posible hombre } \\
\text { (secundario) }\end{array}$ & & $\begin{array}{c}1 \text { vaso liso } \\
1 \text { cuenco } \\
1 \text { mortero de arenisca } \\
\text { ¿1 punzón? }\end{array}$ \\
\hline $\begin{array}{l}\text { Humanejos } \\
\text { (UE 1835) }\end{array}$ & 1 ( \pm 20 años) & $\begin{array}{l}\text { 1. derecho } \\
\text { 2. O-E., cara al SO. } \\
\text { 3. flexión contraída }\end{array}$ & $\begin{array}{l}1 \text { varón adulto } \\
\text { maduro } \\
\text { (40 años })\end{array}$ & & 1 punzón \\
\hline $\begin{array}{l}\text { Humanejos } \\
\text { (UE 1166) }\end{array}$ & 1 (18-20 años) & $\begin{array}{l}\text { 1. derecho } \\
\text { 2. O-E, cara al S } \\
\text { 3. flexión contraída }\end{array}$ & & $\begin{array}{c}1 \text { ( } 7 \text { años } \pm 24 \text { meses }) \\
1 \text { (18 meses } \pm \\
6 \text { meses }) \\
1 \text { (4 años } \pm 12 \text { meses })\end{array}$ & $\begin{array}{l}\text { Cinabrio } \\
1 \text { punzón } \\
1 \text { puñal } \\
1 \text { vaso liso }\end{array}$ \\
\hline $\begin{array}{l}\text { Humanejos } \\
\text { (UE 1701) }\end{array}$ & 1 (20 años) & $\begin{array}{l}\text { 1. izquierdo } \\
\text { 2. S-N, cara al O } \\
\text { 3. flexión contraída }\end{array}$ & & & $\begin{array}{c}1 \text { collar de piedras verdes } \\
2 \text { punzones } \\
1 \text { puñal } \\
\text { cinabrio } \\
3 \text { recipientes lisos } \\
1 \text { afilador }\end{array}$ \\
\hline $\begin{array}{l}\text { La Magdalena } \\
\text { (UT 4600) }\end{array}$ & $\begin{array}{l}\frac{\text { N. Superior: }}{1 \text { adulta-joven }} \\
\begin{array}{l}1 \text { senil } \\
\text { N. inferior: }\end{array}\end{array}$ & $\begin{array}{c}\text { N. Superior: } \\
\text { 1. izquierdo } \\
\text { 2. SE-NO, ¿cara al O? } \\
\text { 3. flexión contraida } \\
\text { N. Inferior } \\
\text { Restos parciales (secundaria) }\end{array}$ & & & $\begin{array}{c}\text { N. inferior: } \\
1 \text { gran vaso Ciempozuelos } \\
1 \text { olla lisa } \\
1 \text { cuenco liso }\end{array}$ \\
\hline
\end{tabular}

Tab. 1. Relación de tumbas campaniformes con mujeres discutidas en el presente trabajo con indicación de la edad, colocación y orientación de los cuerpos, restos de otros individuos y ajuares asociados.

de cobre: un puñal foliáceo y dos punzones en un caso; un puñal de lengüeta y un punzón, en otro. En definitiva, unas donaciones que se encuentran en las tumbas campaniformes más destacadas. La única diferencia sustancial es que la vajilla funeraria de los ajuares se compone de recipientes lisos de morfologías sencillas y sus ornatos personales no están realizados ni en oro ni en marfil.

Una de estas dos tumbas de Humanejos, UE 1701 , pertenece a una mujer joven de alrededor de 20 años, inhumada individualmente en una fosa amplia y poco profunda (Fig. 9a, b). Está colocada con todo cuidado en decúbito lateral izquierdo con las piernas contraídas, además de estar cubierta de cinabrio y adornada con un collar de cuentas de piedras verdes (Fig. 4b). Sus restos han proporcionado una datación de $3800 \pm \mathrm{BP}$ (Ua 40222) con una calibración a $2 \sigma$ de 2250-2130. Sostenía en una mano un puñal foliáceo de cobre (Fig. 5b) y completaba el ajuar con dos punzones también de cobre (Fig. 5f, g), varios recipientes, entre ellos una gran olla o tinaja además de una 
piedra de afilar (Fig. 4a). La esqueletización del cadáver debió de producirse en un espacio sin colmatar lo que explica un cierto desplazamiento de algunos huesos torácicos hacia los pies que pudo producirse en los primeros momentos de la descomposición del cadáver y antes de que la fosa quedara sellada con tierra de manera definitiva.

El segundo caso es de otra mujer joven (UE 1166), de entre 18 y 20 años que se inhumó, acompañada de tres individuos infantiles de corta edad, en una gran fosa de planta circular y escasa profundidad (Fig. 9c). Los enterramientos, posiblemente simultáneos, se realizaron siguiendo un estricto y ordenado guión que consistió en depositar los cuerpos en decúbito lateral y perfecta alineación en paralelo en el centro de la estructura. Para ello el enterrador/es debió de bajar a la fosa y depositarlos cuidadosamente en el punto prefijado. El traslado se hizo sujetando los cuerpos en posición horizontal, quizás envueltos en un sudario o simplemente atados con cuerdas o ligamentos. Además, se encontraron escasos restos de otro individuo adulto del que no se ha podido determinar ni edad ni sexo. No sabemos si corresponden a un traslado desde otra tumba o a una inhumación en la propia tumba que se removió al realizarse los cuatro enterramientos primarios documentados. La datación obtenida de un resto óseo de la mujer es de $3959 \pm 34 \mathrm{BP}$ (Ua 40220) con una calibración a $2 \sigma 2580-2340$ cal BC.

Los individuos infantiles en decúbito lateral derecho, se encontraban mirando hacia el Norte, mientras que la mujer estaba también en decúbito lateral derecho pero con la cabeza vuelta al Sur, mirando hacia los niños. Salvo una ligera desviación del eje del cuerpo de la adulta, todos fueron colocados con la cabeza orientada en dirección $\mathrm{NE}$, aproximadamente hacia el solsticio de invierno. Tanto la mujer como los infantiles de menor edad, 18 meses y cuatro años respectivamente, tenían restos de cinabrio. El ajuar estaba compuesto por diferentes recipientes colocados a los pies de cada uno de los cuerpos, pero es de destacar que el infantil de 4 años poseía un punzón de cobre (Fig. 5h), además de un collar de piedras verdes. Más destacable es el ajuar de la mujer que sostenía en sus manos un punzón (Fig. 5d) y un puñal de cobre (Fig. 5a), en coincidencia con la donación de la mujer antes descrita.

La tabla 1 resume las tumbas con mujeres seleccionadas para este estudio.

\section{LAS MUJERESY SU RECONOCIMIENTO SOCIAL}

\subsection{Las características físicas de las mujeres campaniformes y lo que nos cuentan sus contextos}

Los estudios paleoantropológicos se enfrentan a dificultades como la problemática conservación de los huesos, el carácter de urgencia de las intervenciones $\mathrm{y}$, sobre todo, la necesidad de realizar numerosos análisis que den cuenta de la gran complejidad y variabilidad social de los individuos inhumados. En este marco a medida que estos estudios se han ido incorporando a la Arqueología funeraria en general y a la del horizonte campaniforme en particular, el número de tumbas femeninas individuales, o acompañadas de niños o de varones adultos, ha ido aumentando exponencialmente como evidencian nuestros estudios en los 3 yacimientos madrileños. De ellos destacamos los siguientes aspectos:

1. Según se desprende del estudio de Gómez et al. (2011), reflejado en la selección de tumbas de la tabla 1, en las del Camino de las Yeseras al menos 4 de los 20 individuos con ajuares campaniformes son mujeres lo que supone alrededor de un $20 \%$, el $45 \%$ son varones (8) y el $35 \%$ restante son infantiles (3) y adultos (4) sin asignación sexual. Si se eliminan las dos últimas categorías, no deja de sorprender que los individuos masculinos campaniformes sólo duplican a las féminas inhumadas. En cambio en Humanejos, tomando los resultados del mismo estudio, los infantiles suponen cerca del $25 \%$ y los varones alcanzan casi el $53 \%$ y las mujeres un $(22 \%)$ una de ellas inhumada algún tiempo después de haberse enterrado el varón a quien se dedicó la importante cámara en la que se encuentra.

En el extremo opuesto destaca la proporción de mujeres en La Magdalena (Alcalá de Henares). Allí las inhumaciones existentes en las 5 tumbas excavadas han entregado un total de 11 cuerpos $\mathrm{y}$, "al contrario de lo que ocurre en los yacimientos mencionados, el grupo...está principalmente formado por mujeres" (Cabrera et al. 2012: 37), afirmación que se podrá argumentar con mas solidez cuando finalicen los estudios antropológicos. En otros trabajos de síntesis sobre el campaniforme en Francia, también se ha constatado una presen- 
cia femenina desigual en el ámbito funerario que es un 25\% inferior a la de los hombres (Salanova 2011: 135-137). Así mismo, en los análisis antropológicos del nivel III (campaniforme) del túmulo de La Sima los únicos restos que han podido ser sexados pertenecen a dos mujeres (de 18-30 años y 25-40 años respectivamente) (Rojo et al. 2005b: 172). En la todavía más próxima necrópolis de Las Higueras, en la provincia de Toledo, las mujeres están presentes en enterramientos múltiples de marcado carácter familiar, en particular en el conjunto de la cueva 3 (Bueno et al. 2005, 2012) certificando la constante presencia femenina en tumbas campaniformes incluso, como en este caso, con importantes ajuares. En la misma línea inciden los datos de 4 tumbas campaniformes de La Vital: dos masculinas, una femenina y una de un individuo no sexado (Roca de Togores 2011 y García Puchol et al. 2013: 268).

Los estudios antropológicos confirman, por tanto, que también las mujeres son beneficiarias de pompas fúnebres vinculadas al campaniforme aunque su presencia puede variar de unos yacimientos a otros, siendo las tumbas individuales, excepcionales. No descartamos que estas diferencias puedan tener un carácter local, familiar e incluso cronológico (Andrés 2012). A la espera de los resultados antropológicos definitivos del yacimiento de La Magdalena, hay que señalar la superioridad numérica de las mujeres (Heras et al. 2011) que añadiría una visión distinta a los conceptos sobre la sociedad campaniforme tradicionalmente asumidos.

En general, es también destacable, la diferencia de edad en las inhumaciones realizadas en pareja donde los varones son adultos maduros, edad que sólo alcanzan de forma excepcional las mujeres, pues la mayoría de ellas rondan los 20-25 años. Estos resultados son también válidos para los cuatro individuos recuperados en la famosa necrópolis de Ciempozuelos, dos de los cuales, al menos, 2 son mujeres jóvenes y uno es un varón maduro (Sampedro y Liesau 1998). Esta esperanza de vida es muy similar a la de la población femenina sincrónica sin campaniforme (Gómez et al. 2011).

La frecuencia de mujeres asociadas a infantiles apunta a una mortandad vinculada a problemas de parto o a procesos de rápida evolución derivados de las etapas posteriores relacionadas con el período de lactancia y con una edad de procreación muy temprana, coincidente con la edad fértil (Esparza et al. 2012: 307). Todos ellos son aspectos habituales en las poblaciones preindustriales. Los campaniformes comparten esa circunstancia con sus coetáneos no campaniformes donde también son frecuentes las asociaciones de enterramientos de mujeres con los varones adultos, infantiles o con ambos. Es decir se quiere mantener unidos a determinados miembros de la unidad familiar con la mujer como centro. Incluso en el caso campaniforme hay mayor insistencia a este respecto, debido a los depósitos secundarios incompletos de hombres junto a mujeres, que evidencian un proceso de esqueletización en otro lugar.

Aún siendo todavía muy parciales los resultados de los estudios de paleodietas, el muestreo en una docena de individuos de Camino de las Yeseras indica que la alimentación de los no campaniformes se caracteriza por un mayor consumo de cereales y escasez de lácteos. Pero también entre los campaniformes se observan diferencias llamativas como que todos los individuos del Área funeraria 1 (hombres y mujeres) son los mayores consumidores de carne. Así mismo, los dos varones campaniformes inhumados en los hipogeos de ambas áreas, es decir en las tumbas que han requerido una importante inversión de fuerza de trabajo y con los ajuares más ricos, destacan por una mayor ingesta de lácteos. Los otros campaniformes tienen, en general, una dieta vegetal más rica y variada que los no campaniformes (Trancho y Robledo 2011: 148). Las diferencias de alimentación entre individuos de un mismo grupo han sido también detectadas en comunidades calcolíticas de otras zonas, como las abulenses (Fabián 2006: 440), certificándose la variabilidad de las dietas ya documentadas en la necrópolis de las Higueras (Bueno et al. 2012: 65-68).

Si la edad del óbito no distingue a las mujeres con o sin campaniforme, en Camino de las Yeseras parece advertirse algunas diferencias en sus tareas cotidianas: las fuertes inserciones musculares se encuentran con frecuencia en los brazos de las mujeres sin campaniforme, no se observan entre la población femenina con campaniforme. En cambio en La Magdalena, sí son apreciables "tanto en los hombres como en las mujeres" campaniformes y no campaniformes (Cabrera et al. 2012: 38). ¿Se trata de evidencias que pueden indicar distintos hábitos locales? o ¿responden a la práctica de actividades físicas diferenciadas según

Trab. Prehist., 72, N. ${ }^{\circ}$ 1, enero-junio 2015, pp. 105-125, ISSN: 0082-5638

doi: $10.3989 /$ tp. 2015.12146 
el nivel y las circunstancias sociales de cada una de las mujeres?

También en relación con el estatus campaniforme, se desconoce si ellas pudieran portar algún atuendo específico, al no recibir en los ajuares funerarios elementos de adorno imperecederos como los botones de marfil o hueso con perforación en V. Un ejemplo singular es el de la mujer de Camino de las Yeseras (Área Funeraria 2) que muestra una deformación craneal intencionada producida por un entablillamiento a la altura del frontal para obtener un ensanchamiento lateral del cráneo de forma piriforme. La excepcionalidad del caso no permite, de momento, llegar a mayores inferencias en los criterios que pudieran indicar la motivación de este acto intencionado, aunque sí deja patente una marcada diferencia en el aspecto de esta mujer (Blasco et al. 2009; Gómez et al. 2011). De todas formas, en el horizonte campaniforme, se han documentado otros actos relacionados con la manipulación de la cabeza, como el de la necrópolis de Ciempozuelos donde se pudo documentar una trepanación craneal en vida de un varón maduro (Liesau y Pastor 2003).

Otro aspecto interesante a destacar es la retirada y traslado de restos esqueléticos de unas tumbas a otras, incluso posibles reaperturas de las tumbas para introducir nuevos cuerpos. Son manifestaciones en general poco tratadas que requieren estudios exhaustivos e intervenciones de los yacimientos en extensión. En numerosas ocasiones resulta imposible discriminar en las tumbas alteradas, si su estado se debe a meros expolios, o a aperturas posteriores de los propios grupos campaniformes con la intención de retirar objetos y huesos de sus ancestros que posteriormente son incorporados a otros contextos. Este tipo de prácticas no son novedosas. Se constatan desde el Neolítico y Calcolítico peninsular (Andrés 2005; Clop 2010), pero parecen tener también una especial incidencia en el horizonte campaniforme europeo (Gibson 2004), limitando los resultados de los estudios antropológicos.

Estas sustracciones y recolocaciones han sido practicadas de forma sistemática en Camino de las Yeseras, se trata sobre todo de traslados parciales de esqueletos masculinos mientras que las cuatro féminas documentadas corresponden a inhumaciones primarias intactas (Liesau et al. 2014) (Tab. 1). En la Magdalena ocurre todo lo contrario. En el nivel inferior de una de las tumbas, sólo hay restos parciales de dos cuerpos, al menos uno de ellos femeninos, debido a su traslado o remoción con expolio. Tras ello, fue nuevamente sellada, depositándose en un nivel superior dos cuerpos femeninos, cuyo cráneo fue probablemente retirado un tiempo después (Fig. 7).

Ninguna de las mujeres fue merecedora de ser depositada en las estructuras tumbales más monumentales, como los hipogeos que por sus magnitudes, profundidad y costosos sistemas de cierre, marcan claras diferencias en relación con las demás tumbas agrupadas en las áreas funerarias campaniformes (Camino de las Yeseras). Cuando son inhumadas de forma individual o con un infante, las mujeres se encuentran en pequeñas covachas $y$, en menor medida, en tumbas de fosa colectivas (Humanejos y La Magdalena). Por el contrario, cuando están subordinadas a destacados varones, con ajuares significativos, se inhuman en tumbas más monumentales (Humanejos).

No obstante, los ajuares funerarios de las mujeres campaniformes destacan frente a otras tumbas femeninas no portadoras de dicha cerámica, al ser poseedoras de un tipo de vajilla (Fig. 3) más o menos costosa y de objetos relacionados con unos rituales específicos, vinculados muchas veces a alimentos transformados (Guerra Doce 2006; Rojo et al. 2006). Estos rasgos se asocian a la identidad campaniforme, si es que "la construcción de las identidades"...es parte de un grupo de individuos que se identifican y reafirman constantemente en sus propias prácticas sociales y no en las de los/as otros/as" (Escoriza 2007: 206). Aún siendo prematuro establecer categorías asociadas en función de los tipos y calidad de las vajillas campaniformes, al menos para Camino de las Yeseras podemos constatar que en las inhumaciones femeninas hay una mayor frecuencia de cuencos, incluso superpuestos, siendo excepcionales los vasos. Así mismo, la mayoría de los recipientes de ajuares funerarios destacan por una baja calidad de las pastas, acabados toscos y las escasas o nulas decoraciones (Blasco et al. 2005; 2009; Vega et al. 2010).

Estas observaciones pueden ser discordantes con algunas opiniones en las que se propone que las diferentes técnicas de fabricación y variantes decorativas en las cerámicas campaniformes se debían fundamentalmente a que fueron elaboradas por mujeres y su distribución a escala local o regional podía estar determinada en función 
de los intercambios, alianzas matrimoniales, etc. (Brodie 1997). Aquí la Etnoarqueología ha aportado interesantes aunque discutibles perspectivas (Garrido 2000: 101-107). Otros manifiestan que la cerámica debe ser considerada como un elemento fundamentalmente vinculado a las exequias, mientras el resto de los objetos, como el mortero, la piedra de afilar (Fig. 4a, c) o los punzones (Fig. 5c-h) pudieron haber sido utilizados en vida por los difuntos. Sin duda alguna, los punzones serían objetos de gran valor por estar realizados en cobre, siendo frecuente su incorporación a las tumbas femeninas, como lo son durante la Edad del Bronce, concretamente en el ámbito argárico donde ya E. Siret y L. Siret (1890: 184) reconocieron su vinculación a inhumaciones femeninas. Estudios posteriores confirman y distinguen diferentes tipos y su asociación con otros ajuares (Lull y Estévez 1986; Montón 2010; Pérez 2011; Schubart 2012).

La presencia de elementos de molienda en tumbas femeninas, campaniformes y no campaniformes se ha justificado por el hecho de que "la emergencia de la desigualdad política se canalizó a través de formas de trabajo y prácticas de relación social preexistentes y que, probablemente, exigió nuevas formas de presión sobre quienes, tradicionalmente, realizaban estas actividades: básicamente, sobre las mujeres...[pues] cualquier cambio dirigido a la intensificación en las formas de producción relacionadas con las actividades de mantenimiento, incluyendo las relacionadas con la creación de la vida, ha implicado un cambio y presión directos sobre las mujeres que las realizaban" (González Marcén et al. 2007: 176).

Las observaciones realizadas en los ajuares femeninos nos permiten en cierta medida proponer para las tumbas campaniformes una categorización similar a la que se ha observado para las argáricas. Como en ellas, la mayoría de las mujeres pueden adscribirse a la categoría 3 (Lull y Estévez, 1986, 450), al incluir generalmente un punzón y vasija/s o sólo estas últimas, pero habitualmente, con la característica ornamentación campaniforme. Parece, por tanto, que su situación no sería muy diferente a la propuesta para las féminas argáricas. Como ellas, también pueden estar excepcionalmente asociadas a varones de máximo rango o consideración, caso de la cámara UE 1853 de Humanejos.

\subsection{Ajuares singulares: mujeres sin vajilla campaniforme y con puñales (Figs. 5a, b y 9)}

En este conjunto de tumbas femeninas destacan dos del yacimiento de Humanejos que no poseen vajilla campaniforme, pero su ritual de enterramiento y algunos de los componentes del ajuar muestran estrechas relaciones con las praxis campaniformes. Nos referimos a los punzones, cinabrio/colorante rojo, y sobre todo a las armas cuya presencia merece una discusión más amplia. Como se ha indicado, "en Prehistoria, lo que se denomina armas se ha asociado casi siempre a los hombres, incluso sin conocer el sexo de los cadáveres asociados a las mismas. El mero hecho de aparecer un instrumento bélico permitía considerar masculino al acompañante del ajuar. Ciertamente los hombres estuvieron vinculados a las armas en muchas ocasiones, pero es preciso contar con evidencias sólidas, ya que en algunos casos las mujeres también fueron protagonistas de episodios de lucha" (Sanahuja 2007: 194). En efecto, en Humanejos podemos confirmar que, al menos dos de las mujeres inhumadas fueron poseedoras de "armas convencionales".

Por otra parte, Lemercier apunta que la presencia de armas no es una seña de identidad de los campaniformes, puesto que sólo algunos individuos las poseen y tampoco es una regla general que esté vinculada a los ajuares más destacados. Plantea dos preguntas fundamentales " ¿se trata de armas y podemos por tanto hablar de guerreros? $\mathrm{O}$ ¿La actividad ligada a las armas no podría ser otra diferente como es la caza? ¿Estas armas son funcionales? ¿Se trata únicamente de marcadores de estatus o de objetos destinados para ser entregados en el ajuar funerario?" (Lemercier 2011: 136). Son enfoques a los que se podrían añadir puntos de vista manejados por otros autores, como concebirlas simplemente como una forma de amortizar el metal, en cuyo caso el horizonte campaniforme tendría mayor capacidad que cualquier otro grupo del Calcolítico y la Edad del Bronce en las tierras del interior peninsular (Carmona et al. 2010). También al tratarse del primer horizonte en el que aparentemente se documenta una actividad metalúrgica significativa, el metal puede tener una connotación especial y quizás una utilización, si no exclusiva, al menos fundamentalmente funeraria.

Trab. Prehist., 72, N. ${ }^{\circ}$ 1, enero-junio 2015, pp. 105-125, ISSN: 0082-5638

doi: $10.3989 /$ tp.2015.12146 
Aunque la presencia de "armas" en tumbas femeninas no representa una novedad, sí es destacable que nos encontramos ante algunos de los ejemplos más antiguos en los que las armas metálicas forman parte de ajuares funerarios de mujeres que, por las similitudes que ofrecen, pueden ponerse en relación con los argáricos de los que pudieron ser un precedente. En dichos contextos las "armas" femeninas se han justificado por "la bisexualidad de los puñales/cuchillos" (Lull y Estévez 1986). La introducción de armas en tumbas femeninas tiene sus paralelos en contextos no campaniformes tanto europeos como peninsulares de inicios del II a.C. Del ámbito argárico son bien conocidos los hallazgos de puñales en inhumaciones masculinas, pero también femeninas, tanto que en algunos yacimientos como Fuente Álamo aparecen indistintamente en inhumaciones de ambos sexos, preferentemente a la altura de la cintura, y en el caso de las mujeres, suelen estar asociados a punzones y corresponder a inhumaciones de mayor rango social (Schubart 2012: 72). En El Argar, El Oficio, Gatas o Peñalosa alguno de los puñales presenta incluso adornos o remaches de plata (Siret y Siret 1890; Lull 1983; Alarcón y Sánchez 2012). Fuera de la Península también se han recuperado puñales en ajuares de enterramientos pertenecientes a las mujeres "mejor dotadas" (Elbiali 2011: 211; Peška 2013: 64). En este contexto no resulta raro que algunas de las tumbas campaniformes femeninas incorporen un puñal en su ajuar, si bien como ocurre en otros ámbitos, siguen siendo minoría si las comparamos con las tumbas masculinas que las poseen (Lemercier 2011: 131).

Otra cuestión distinta es si las "armas" tienen el mismo significado en manos de mujeres o de hombres. En caso afirmativo, "algunas mujeres, al menos las de las clases superior e intermedia, también fueron inhumadas con ellas. En consecuencia, ciertas mujeres también portaban armas" (Sanahuja 2007: 199). Pero "si los puñales en tumbas femeninas no se pueden considerar armas, se debe dejar de clasificar [también] a estas piezas como armas en el caso de estar asociadas a enterramientos masculinos y denominarlas cuchillos en los femeninos" (Sanahuja 2007: 199).

En este horizonte, las armas parecen tener un significado distinto para hombres y mujeres; en los ajuares masculinos son frecuentes las panoplias que incluyen puñales, puntas de flecha, brazales y, excepcionalmente alabardas, mientras que a las mujeres se les entrega un puñal y, en ningún caso vinculado a otras armas, salvo a los punzones. Pero la adscripción de los punzones como ajuar femenino tampoco es exclusiva como lo demuestra un hallazgo reciente de un punzón asociado a un varón campaniforme del yacimiento burgalés de El Hundido (Alonso 2013). En casos similares documentados en las Islas Británicas han sido interpretados de forma muy pragmática, argumentando que los punzones representan instrumentos de artesanos dedicados al trabajo de la piel. Sin embargo, Brodie discute ese "énfasis en asignar esta tarea a una actividad masculina" y matiza acertadamente que "si los punzones se emplearon para tales menesteres tan sólo demuestran que también fueron utilizados en actividades meramente domésticas" (Brodie 1997: 304).

Queremos insistir algo más en esta funcionalidad múltiple de los punzones pues, no sólo se emplearían en el trabajo de diferentes materiales orgánicos, sino también en otras tareas domésticas importantes como es el despiece de animales de talla media y grande. Algunos puñales pueden cumplir también esa función. Igualmente, ambos objetos se utilizarían en un enfrentamiento cuerpo a cuerpo. Precisamente los punzones destacan por sus puntas aguzadas y no descartamos su empleo eficiente como armas letales incisas. Independientemente de su uso, en este horizonte se perfila su gran estima y/o valor simbólico para convertirse durante siglos en un ajuar funerario distintivo de lo femenino, además de revelar su carácter hereditario como evidencia el equipo funerario de uno de los infantes campaniformes de Humanejos.

Durante la Edad del Bronce la disimetría entre ajuares masculinos y femeninos se manifiesta de una manera todavía más evidente en su reflejo de la reafirmación del guerrero con la ampliación de las panoplias (espadas, puntas de lanza (Elbiali 2011: 215). En paralelo, algunas mujeres mantienen la inclusión del puñal o el cuchillo y excepcionalmente la alabarda, objetos que serían "marcadores de estatus social y quizás religioso, aunque no se puede descartar una función defensiva" (Elbiali 2011: 217).

Destacar también que las tumbas de mujeres con armas es un fenómeno de amplio recorrido cronológico y geográfico y del que todavía conocemos ejemplos actuales como en la Albania rural o Afganistan donde en ciertos casos la pérdida de un varón provoca que una de las mujeres asuma ese rol en la 
familia para que ésta pueda subsistir en esa sociedad patriarcal (Prados 2012a: 10). La Península Ibérica cuenta con los mejores ejemplos en el mundo funerario aristocrático de la Cultura Ibérica "a partir del tránsito del s. V al IV a. C. que culminarán con la visibilidad de la mujer aristocrática a través de sus enterramientos" (Prados 2012b: 238), pese a los problemas que plantea la identificación del género en las tumbas de cremación. El mejor y más espectacular ejemplo, aunque no el único, es el de la conocida tumba de la Dama de Baza, con hasta cuatro panoplias de armas, una manifestación que se ha puesto en el contexto de prácticas similares en otros ámbitos europeos a partir del inicio de la Edad del Hierro (Quesada 2011, 2012).

¿Cómo interpretar estas dos tumbas de Humanejos sin vajilla campaniforme pero con ritual y metalurgia campaniforme? ¿se trata de un fenómeno que quizás tenga una mayor amplitud que el registrado hasta ahora? En ambos casos cabe preguntarse si estas dos féminas pertenecieron a un grupo campaniforme o procedían de otro círculo en el que algunas mujeres tienen ajuares que incluyen armas. Pero si es así, ¿por qué tanto las tipologías de los puñales son campaniformes? ¿Se trata de personajes pertenecientes a los grupos no campaniformes que convivieron con ellos en los que la mujer pudo ostentar el liderazgo y estamos ante un fenómeno de emulación? Lo cierto es que el ritual otorgado a estas dos mujeres: depósito, posición, coloración de los cuerpos y la riqueza del ajuar, sigue un protocolo específico de las comunidades campaniformes que las diferencia de los grupos con los que conviven pero no pertenecen a ellos (Carmona et al. 2010), ¿por qué entonces no exhiben la vajilla campaniforme?

La ausencia de esta vajilla no es una excepción ya que también existen otros enterramientos que han sido interpretados como pertenecientes a este horizonte por poseer un puñal de tipología campaniforme, aunque no les acompañe la característica cerámica decorada. Es el caso de una tumba de la necrópolis de Bernières-sur-mer que ha sido atribuida a un personaje campaniforme a pesar de que, como en las tumbas que nos ocupan, no tiene la característica vajilla y se encuentra en un yacimiento donde también hay ajuares con cerámicas campaniformes y sin ella (Nöel 2011: 51, fig. 31, 2). Aunque en el yacimiento francés no se ha podido determinar el sexo del individuo inhumado, en nuestros dos casos, lo llamativo es que las destinatarias de tales exequias y donaciones son precisamente mujeres que han quedado excluidas de los enterramientos campaniformes clásicos más destacados del yacimiento.

\section{UN APUNTE MÁS: ¿PODEMOS SEGUIR HABLANDO DE UNOS PATRONES HOMOGÉNEOS EN LAS PAUTAS FUNERARIAS CAMPANIFORMES?}

Se ha manifestado en no pocas ocasiones que cuando las condiciones de estudio de los rituales funerarios campaniformes resultan algo más favorables para poder profundizar en las posibles diferencias sociales éstos "constituyen un conjunto de tipos que se repite, independientemente del contexto cultural en el que se sitúe, simultáneamente en gran parte de Europa (Hernando 2002: 160-161). Es decir, "el campaniforme 'unifica' a quien se asocia a él. Pero resulta paradójico que quien empieza a diferenciarse de su grupo utilice, sin embargo, elementos que le identifiquen a/con otros... Así pues, si se empezaba a manifestar alguna diferencia con los del propio grupo, sería imprescindible manifestar semejanzas con otros. Y la semejanza está implícita entre quienes disfrutan de las mismas diferencias entre sus grupos respectivos, es decir entre las distintas jerarquías del mundo europeo occidental" (Hernando 2002: 160-161). Desde este supuesto, los grupos campaniformes pretenden diferenciarse de sus convecinos, un empeño que se materializa en los rituales y ajuares funerarios mediante la donación de determinados objetos y materias primas singulares y, con frecuencia, costosos. Es cierto que estos ajuares son similares a los pertenecientes a las élites de grupos alejados a grandes distancias geográficas, pero no se ha llamado la atención sobre en qué medida esta diferenciación afecta por igual a hombres y a mujeres.

Otro aspecto a destacar es que esta homogeneidad de los grupos campaniformes debe ser asumida con ciertas reservas ya que podría ser más aparente que real. Empieza a observarse que no en todas las necrópolis campaniformes los enterramientos "más ricos" o simplemente los "más singulares" se identifican con los mismos objetos, ni tampoco con el mismo número de elementos $\mathrm{y}$ riqueza, si por riqueza entendemos número $\mathrm{y}$ 
rareza de determinados ajuares. Está sobradamente contrastado que tampoco en una misma necrópolis todos los enterramientos ostentan un rango similar al asociarse a ajuares y tumbas de "coste" muy asimétrico, tanto por la inversión en fuerza de trabajo en la elaboración de la propia tumba como por la rareza de los objetos o materias primas amortizadas. El hecho de pertenecer a ese grupo destacable no parece ser sinónimo de ser merecedor de un determinado nivel estándar de objetos. Ello parece lógico pues no todos sus componentes presentan el mismo prestigio o influencia social, de manera que las donaciones probablemente se ajustan al mérito, rango y/o oficio de cada individuo.

Mucho más llamativa es la importante variabilidad que se advierte entre los diferentes cementerios campaniformes como puede observarse en los tres yacimientos que nos sirven de apoyo a este trabajo. Así mientras en Humanejos se construyen auténticas cámaras independientes de grandes dimensiones, en La Magdalena las tumbas, también aisladas unas de otras, son más modestas y en Camino de Las Yeseras, conviven hipogeos y covachas asociadas dentro de grandes estructuras que podrían tener un carácter de panteón familiar o grupal.

De todo ello se desprende que la aludida homogeneidad es más aparente que real, ya que incluso entre las propias "élites" marcan diferencias que llegan a ser tan notables como las que pueden existir entre campaniformes y no campaniformes contemporáneos. Ni siquiera el liderazgo parece manifestarse de manera similar, aunque a primera vista la variabilidad queda minimizada por la reiteración de los modelos formales y decoraciones de la cerámica y por el tradicional protagonismo de las panoplias metalúrgicas y elementos ornamentales.

Por otra parte, cabe señalar que pocas veces se ha tenido en cuenta que, junto a las posibles diferencias sexuales, hay condiciones de vida distintas entre las mujeres de un mismo grupo, dependiendo del estatus social por razones hereditarias o de consanguinidad, que pueden llegar a ser incluso más notorias que las que se derivan de las existentes entre varones y féminas. La supuesta similitud parece, por tanto, quedar reducida a la presencia de un determinado tipo de recipientes, especialmente los cuencos y en menor medida los vasos y las armas. Pero tampoco podemos afirmar de manera rotunda que todos los objetos de "lujo y prestigio" que identifican a los líderes campaniformes, de entre el resto del grupo, sean exclusivamente masculinos, como se ha dicho (Hernando 2007: 172).

\section{CONCLUSIÓN}

Queda por tanto comprobado a partir de los yacimientos estudiados, que la mujer fue parte integrante de los grupos campaniformes con ciertos derechos y que, al menos algunas de ellas, disfrutaron de unas condiciones de vida privilegiadas. No obstante, falta por entender si su menor presencia se debe a la parcialidad de las excavaciones, a la falta de estudios antropológicos, a la imposibilidad de asignación sexual o a un factor significativo real, a la hora de aproximarnos a su relevancia social. Otro aspecto a considerar, y que puede influir decisivamente en la obtención de resultados concluyentes, es que parece probable que no todos los miembros del grupo campaniforme tuvieran entre los componentes del ajuar la vajilla que los identifica, bien porque en su sepelio no se celebraran las libaciones y/o banquetes en los que se usaban, bien porque no hubiera disponibilidad en el momento de la inhumación y se sustituyera por recipientes comunes o por piezas realizadas en madera o en otros materiales de origen orgánico, sin descartar que los rituales fúnebres de algunas mujeres pudieran seguir otras pautas que no requieren vajilla decorada antes de su cocción.

De todos estos ejemplos recopilados en los yacimientos de Camino de las Yeseras y Humanejos se desprende que aunque los varones, tanto jóvenes como seniles, fueron objeto de un mayor reconocimiento, manifestado a través de amplias y valiosas donaciones, también algunas mujeres desempeñaron un papel destacado dentro del grupo, llegando a ser merecedoras de objetos de cierto valor como son los punzones en calidad de ajuar funerario de prácticas posteriores.

Aunque hasta ahora faltaban en los ajuares femeninos armas en cobre, lotes importantes de vajillas $\mathrm{y}$, sobre todo el empleo de cinabrio o los adornos de marfil. El registro de las tumbas de las dos mujeres de Humanejos y de una de las exhumadas en La Magdalena, transforman de manera sustancial la visión tradicional de la mujer campaniforme. ¿Estamos ante un tratamiento 
diferenciado por razón de género y también pudo haber mujeres que alcanzaron la cúspide social? o lo que es más relevante ¿estamos ante una consideración distinta de la mujer entre los grupos no campaniformes que entre los campaniformes? $\mathrm{Si}$ este segundo supuesto fuera el correcto, no cabe duda que los rituales campaniformes fueron considerados como propios de los personajes más relevantes y sus vecinos trataron de emularlos para ensalzar también a sus lideresas.

Somos conscientes que esta aproximación de enorme interés requiere mayor atención desde los trabajos de campo y los estudios de laboratorio para poder definir si la mujer tuvo el mismo significado entre los campaniformes y sus vecinos $o$, lo que es lo mismo, si entre la población que se muestra "más tradicional" la mujer llegó a desempeñar el papel destacado que los campaniformes asocian a los varones. En segundo lugar, hay que saber hasta qué punto la jerarquía campaniforme tuvo su continuidad en las siguientes generaciones y si se prolongó el manejo de las armas como argumento de poder. Por último, conviene averiguar si el fenómeno campaniforme mantuvo unos comportamientos sociales similares durante su medio milenio de vigencia, especialmente en la consideración de la mujer, o si ésta con el tiempo fue ganando relevancia en los rituales funerarios.

\section{AGRADECIMIENTOS}

Trabajo financiado por el projecto $\mathrm{I}+\mathrm{D}+\mathrm{i}$ HAR2011-28731: "Las sociedades calcolíticas y su marco temporal en la región de Madrid. Una revisión a la luz de nuevos datos". Ministerio de Economía y Competividad. Gobierno de España. Agradecemos igualmente a Jorge Vega y Roberto Menduiña de la empresa Argea S.L. el habernos facilitado la documentación y los materiales de la campaña de excavación del 2006/07 de Camino de las Yeseras.

\section{BIBLIOGRAFÍA}

Alarcón, E. y Sánchez, M. 2012: “Mujeres e identidad: el cuerpo y su contribución a la construcción de identidades en el mundo argárico”. En L. Prados (ed.) La Arqueología funeraria desde una perspectiva de género. Col. Estudios 145 Universidad Autónoma de Madrid 2. Madrid: 72.

Alonso, C. 2013: "Las tumbas campaniformes del monumento funerario "El Hundido" (Monasterio de Rodilla, Burgos). Munibe, 64:1-15.

Andrés, T. 2005: Concepto y análisis del cambio cultural: su percepción en la materia funeraria del Neolitico y Calcolitico. Universidad de Zaragoza. Zaragoza

Andrés, T. 2012:'Identificando la identidad en la Prehistoria por la Prehistoria". Salduie 10: 13-43.

Antón, M. 1897: "Cráneos antiguos de Ciempozuelos". Boletín de la Real Academia de la Historia XXX 467-483.

Blasco, M. ${ }^{a}$ C. (ed.) 1994: El Horizonte campaniforme de la Región de Madrid en el centenario de Ciempozuelos. Patrimonio Arqueológico del Bajo Manzanares 2, Universidad Autónoma de Madrid. Madrid.

Blasco, C.; Baena, J. y Liesau, C. 1998: La Prehistoria madrileña en el Gabinete de Antigüedades de la Real Academia de la Historia. Patrimonio arqueológico del bajo Jarama 3, Universidad Autónoma de Madrid. Madrid.

Blasco, C. Baena J. y Ríos, P. 2007-2008: "Materias primas de elementos de molienda como marcadores de la ampliación de las áreas de captación durante el horizonte campaniforme. El ejemplo del yacimiento de Camino de las Yeseras". Veleia 24-25: 755-769.

Blasco, C.; Liesau, C.; Delibes; G. Baquedano, E. y Rodríguez, M. 2005: "Enterramientos campaniformes en ambiente doméstico: el yacimiento de Camino de las Yeseras (San Fernando de Henares, Madrid)". En M. Rojo, R. Garrido e I. Martínez (eds.): El Campaniforme en la Península Ibérica y su contexto europeo. Universidad de Valladolid. Valladolid: 457-479.

Blasco, C.; Liesau, C. y Ríos, P. (eds.) 2011: Yacimientos calcolíticos con campaniforme de la Región de Madrid. Nuevos estudios. Patrimonio arqueológico de Madrid 9, Universidad Autónoma de Madrid. Madrid.

Blasco, C.; Liesau, C.; Ríos, P.; Blanco, J. F.; Aliaga, R.; Moreno, E. y Daza, A. 2009: "Kupferzeitliche Siedlungsbestattungen mit Glockenbecher-und Prestigebeigaben aus dem Grabenwerk von El Camino de las Yeseras (San Fernando de Henares, prov. Madrid). Untersuchungen zur Typologie des Grabritus und zu dessen sozialer Symbolik". Madrider Mitteilungen 50: 40-70.

Blasco, C. y Ríos, P. 2010: "La función del metal entre los grupos campaniformes: oro versus cobre. El ejemplo de la Región de Madrid". Trabajos de Prehistoria 67 (2): 359-372.

Brodie, N. 1997: "New Perspectives on the Bell-Beaker Culture". Oxford Journal of Archaeology 16, 3: 297314.

Bubner, T. 1976. "Acerca de la población campaniforme de la Península Ibérica". Cuadernos de Prehistoria y Arqueología Castellonense 3: 51-59.

Trab. Prehist., 72, N. ${ }^{\circ}$ 1, enero-junio 2015, pp. 105-125, ISSN: 0082-5638

doi: $10.3989 /$ tp.2015.12146 
Bueno, P.; Barroso, R. y Balbín, R. de 2005: "Ritual campaniforme, ritual colectivo: La necrópolis de cuevas artificiales del Valle de las Higueras, Huecas, Toledo". Trabajos de Prehistoria 62 (2): 67-90.

Bueno, P.; Barroso, R. y Balbín, R. de 2012: 5.000 años atrás. Primeros agricultores y metalúrgicos del Valle de Huecas (Huecas, Toledo). Universidad de Alcalá de Henares. Alcalá de Henares.

Cabrera, M. ${ }^{\text {a }}$ C.; Galera, V. y Heras, C. 2012: "El campaniforme en la sub-meseta sur: Estudio antropológico de los restos esqueléticos de La Magdalena I (Alcalá de Henares)". Preactas de las Novenas jornadas de Patrimonio arqueológico en la Comunidad de Madrid (Alcalá de Henares 2012): 37-38. Madrid.

Cámara, J. A. 2001: El ritual funerario en la Prehistoria Reciente en el Sur de la Península Ibérica. British Archaeological Reports, International series 913. Oxford.

Carmona, E.; Arnaiz, M. A. y Montero, I. 2010: “Consumo de metal durante la Prehistoria Reciente en el centro de la Península Ibérica. Una aproximación a través del análisis de los contextos funerarios en fosa". Trabajos de Prehistoria 67 (2): 337-387.

Castillo, A. del 1928: La cultura del vaso campaniforme. Universidad de Barcelona. Barcelona.

Castro, P. V.; Escoriza, T.; Fregeiro, M. I.; Oltra, J.; Otero, M. y Sanahuja, E. 2006: Contra la falsificación del pasado prehistórico. Buscando la realidad de las mujeres y los hombres detrás de los estereotipos. Instituto de la Mujer del Ministerio de Trabajo y Asuntos Sociales. Madrid. http:/www. mtas.es//mujer/mujeres/estud_inves/649.pdf (consulta 16-I-2015).

Castro, P. V.; Escoriza, T. y Sanahuja, E. 2003: Mujeres y hombres en espacios domésticos. Trabajo y vida social en la Prehistoria de Mallorca (c. 700-500 cal. ANE.). El edificio Alfa de Puig Morter de San Ferragut (Sineu, Mallorca). British Archaeological Reports, International Series 1162, Archaeopress. Oxford.

Cohen, C. 2011: La mujer de los orígenes. Imágenes de la mujer en la Prehistoria occidental. Ed. Cátedra. Madrid.

Delibes, G. 1977: El vaso campaniforme en la Meseta Norte española. Studia Archaeologica 46, Universidad de Valladolid. Valladolid.

Delibes, G. y Herrán, J. I. 2007: La Prehistoria. Biblioteca Básica de Valladolid, Diputación de Valladolid. Valladolid.

Deselaers, H. 1917: “Cráneos eneolíticos de Ciempozuelos". Boletín de la Real Academia de la Historia LXXI: $17-38$.

Desideri, J. y Besse, M. 2010: "Swiss Bell Beaker population dynamics: eastern or southern influences?" Archaeological and Anthropological Sciences 2: 157-173. DOI 10.1007/s12520-010-0037-9

Desideri, J. y Besse, M. 2012: "De la dent à l'individu, du groupe humain à son histoire: le phénomène campaniforme dans le nord de l'Espagne". Bulletins et mémoires de la Société d'Anthropologie de París. 24: 37-50.

Clop, X. 2010: “¿Muertos en movimiento? Datos y reflexiones sobre la gestión de los sepulcros colectivos". Actas del Congreso Internacional sobre el Megalitismo y otras manifestaciones funerarias contemporáneas en su contexto social, económico y cultural. Munibe suplemento 32. San Sebastian: 506-514.

Elbiali, M. D. 2011: "À la recherche du guerrier dans les sépultures du Bronze ancien et moyen (2200-1300 av. J.C.) en Europe centre-occidentale et Italie du Nord". En L. Baray, M. Honegger y M. H. Dias-Meirinho (eds.): L'armement et l'image du guerrier dans les sociétés anciennes. ARTeHIS ed. Dijon: 189-224.

Escoriza, T. 2007: "Desde una propuesta arqueológica, feminista y materialista". Complutum 18: 201-208.

Escoriza, T. 2008: "Presentación: Trazando nuevas rutas desde una Arqueología materialista y feminista". En T. Escoriza M M $^{\mathrm{a}}$. López Medina y A. Navarro (eds.): Mujeres y Aqueología. Nuevas aportaciones desde el materialismo histórico. Homenaje al Profesor Manuel Carrillero Millán, Junta de Andalucía. Almería: 19-58.

Esparza, A.; Velasco, J. y Delibes, G. 2012: "Hum 2005-00139: Planteamiento y primeros resultados de un proyecto de investigación sobre la muerte en Cogotas I'. En J. A. Rodríguez Marcos y J. Fernández Manzano (eds.): Cogotas I. Una cultura de la Edad el Bronce en la Península Ibérica. Universidad de Valladolid. Valladolid. 259-320.

Fabián, J. F. 2006: El IV y III milenio AC en el Valle del Amblés (Ávila). Arqueología en Castilla y León. Monografías 5, Junta de Castilla y León. Salamanca.

García Puchol, O.; Bernabeu, J.; Carrión, Y.; Molina, L1.; Pérez Jordà, G. y Gómez Puche, M. 2013: “A funerary perspective on Bell Beaker period in the Western Mediterranean. Reading the social context of individual burials at La Vital (Gandía, Valencia)". Trabajos de Prehistoria 70 (2): 264-277.

Garrido, R. 2000: El campaniforme en la Meseta central de la Península Ibérica (2500-2000 a.C.). British Archaeological Reports, International Series 892, Archaeopress. Oxford.

Gerhardt, K. 1953: Die Glockenbecherleute in Mittelund Westdeutschland. E. Schweizerbart'sche Verlagsbuchhandlung. Stuttgart.

Gibson, A. 2004: "Burials and Beakers: Seeing the Veneer in Late Neolithic Britain". En J. Czebreszuk (ed.): Similar but Different. Bell Beakers in Europe. Adam Mickiewicz University. Poznan: 173-192.

Gómez, J. L.; Blasco, C.; Trancho, G.; Ríos, P.; Grueso, I. y Martínez, M. ${ }^{\text {a }}$ S. 2011: "Los protagonistas". En C. Blasco, C. Liesau y P. Ríos (eds.): Yacimientos calcoliticos con campaniforme de la Región de Madrid: nuevos estudios. Patrimonio arqueológico de Madrid 9, Universidad Autónoma de Madrid. Madrid: 101-132. 
González Marcén, P.; Montón S. y Picazo, M. 2007: "Continuidad y cambio social en lacultura material de la vida cotidiana". Complutum 18: 175-184

Grupe, G.; Price, T. D. y Söllner, F. 1999: "Mobility of Bell Beaker people revealed by strontium isotope ratios of tooth and bone: a study of southern Bavarian skeletal remains. A reply to the comment by Peter Horn and Dieter Müller-Sohnius. Applied Geochemistry 14: 271-275.

Guerra Doce, E. 2006: "Sobre la función y el significado de la cerámica campaniforme a la luz de los análisis de contenidos". Trabajos de Prehistoria 63 (1): 69-84.

Harrison, R. J. 1977: The Bell Beaker cultures of Spain and Portugal. American School of Prehistoric Research, Bulletin 35. Cambridge Massachussets.

Heras, C.; Galera, V. y Bastida, A 2011: "La fase campaniforme del yacimiento de La Magdalena". En C. Blasco, C. Liesau y P. Ríos (eds.): Yacimientos calcolíticos con campaniforme de la Región de Madrid. Nuevos estudios. Patrimonio arqueológico de Madrid 9, Universidad Autónoma de Madrid. Madrid: 17-22.

Heras, C.; Galera, V. y Bastida, A. 2014: "Enterramientos y ritual funerario en una necrópolis calcolítica con campaniforme en la submeseta sur: El yacimiento de "La Magdalena I (Alcalá de Henares)". Actas de las novenas jornadas de Patrimonio Arqueológico en la Comunidad de Madrid. Dirección General del Patrimonio Histórico. Madrid: 213-227.

Hernando, A. 2002: Arqueología de la identidad. Akal Arqueología. Madrid.

Hernando, A. 2007: "Sexo, Género y Poder. Breve reflexión sobre algunos conceptos manejados en la Arqueología del Género”. Complutum 18: 167-174.

Kunst, M. 2001: "Invasion? Fashion? Social Rank? Consideration concerning the Bell Beaker phenomenon in Copper Age fortifications of the Iberian Peninsula". Bell Beakers today (Riva de Garda 1998): 81-90. Trento.

Lee, E. J.; Makarewicz, C.; Renneberg, R.; Harder, M.; Krause-Kyora, B.; Müller, S.; Ostritz, S.; Fehren-Schmitz, L.; Schreiber, S.; Müller, J.; WurmbSchwark, von N. y Nebel, A. 2012: "Emerging Genetic Patterns of the European Neolithic: Perspectives From a Late Neolithic Bell Beaker Burial Site in Germany". American Journal of Physical Anthropology 148: 571-579.

Lemercier, O. 2011: “Le guerrier dans 1'Europe du III millènaire avant notre ère. L'arc et le poignard dans les sépultures individuelles campaniformes". En L. Baray, M. Honegger y M. H. Dias-Meirinho (eds.): L'armement et l'image du guerrier dans les sociétés anciennes. ARTeHIS ed. Dijon: 121-165.

Liesau, C. y Blasco, C. 2011- 2012: "Materias primas $\mathrm{y}$ objetos de prestigio en ajuares funerarios como testimonios de redes de intercambio en el Horizon- te campaniforme". Cuadernos de Prehistoria y Arqueología de la Universidad Autónoma de Madrid 37-38, I: 209-222.

Liesau, C.; Blasco, C.; Ríos, P.; Vega, J.; Menduiña, R.; Blanco, J. F.; Baena, J.; Herrera, T.; Petri, A. y Gómez, J. L. 2008: “Un espacio compartido por vivos y muertos: El poblado calcolítico de fosos de Camino de las Yeseras (San Fernando de Henares, Madrid)". Complutum 18 (1): 97-120.

Liesau, C. y Moreno, E. 2012: "Marfiles campaniformes de El Camino de las Yeseras (San Fernando de Henares, Madrid)". En A. Banerjee, J. A. López Padilla y T. X. Schuhmacher (eds.): Elfenbeinstudien. Marfil y elefantes en la Península Ibérica y el Mediterráneo occidental. Coloquio Internacional. Museo Arqueológico de Alicante (Alicante 2008). Iberia Archaeologica 16, 1. Darmstadt: 83-94.

Liesau, C. y Pastor, I.: 2003: "The Ciempozuelos Necropolis Skull: A Case of Double Trepanation?". International Journal of Osteoarchaeology 13: 213-221.

Liesau, C.; Ríos, P; Vega, J.; Menduiña y Blasco, C. 2014: "Buscando los ancestros: La manipulación de los restos de las tumbas campaniformes en Camino de las Yeseras (San Fernando de Henares, Madrid)". Actas de las novenas jornadas de Patrimonio Arqueológico en la Comunidad de Madrid. Alcalá de Henares. 137-148. Madrid.

Lull, V. 1983: La cultura de El Argar. Akal Universitaria, Madrid.

Lull, V. y Estévez 1986: "Propuesta metodológica para el estudio de las necrópolis argáricas”. En Homenaje a Luis Siret. Consejería de Cultura de la Junta de Andalucía, Dirección General de Bellas Artes, Ministerio de Cultura. Sevilla: 441-452.

Marcén, P.; Montón, S. y Picazo, M. 2007: “Continuidad y cambio social en la cultura material de la vida cotidiana". Complutum 18: 175-184.

Montón, S. 2010: "Muerte e identidad femenina en el mundo argárico", Trabajos de Prehistoria 67 (1): 117-139.

Nöel, J.-Y. 2011: “Les sépultures individuelles de Bernières-Sur-Mer (Calvados): Une nécropole du debut des âges des métaux". En L. Salanova y Y. Tchérémissinoff (eds.): Les sépultures individuelles campaniformes en France. Gallia Préhistoire XLI ${ }^{\mathrm{e}}$ Supplément, CNRS editions. Paris: 47-55.

Pérez, S. 2011: "Los punzones metálicos en los contextos funerarios argáricos: los casos de Fuente Álamo (Cuevas de Almanzora, Almería) y Cuesta del Negro (Purullena, Granada)". El Futuro del Pasado 2: 63-78.

Peška, J. 2013: “Two new burial sites of Bell Beaker Culture with an exceptional finds from Eastern Moravia/Czech Republic". En P. Prieto y L. Salanova (eds.): Current researches on Bell Beakers. Proceedings of the $15^{\text {th }}$ International Bell Beaker Conference: From Atlantic to Ural (Poio, Pontevedra, Galicia, Spain 2011). Santiago de Compostela: 61-72.

Trab. Prehist., 72, N. ${ }^{\circ}$ 1, enero-junio 2015, pp. 105-125, ISSN: 0082-5638

doi: $10.3989 /$ tp. 2015.12146 
Prados, L. 2012a: "Prólogo". En L. Prados (ed.): La Arqueología funeraria desde una perspectiva de género. Col. Estudios 145, Universidad Autónoma de Madrid 2. Madrid: 7-20.

Prados, L. 2012b: "Si las muertas hablaran...Una aproximación a los contextos funerarios de la Cultura Ibérica". En L. Prados (ed.): La Arqueología funeraria desde una perspectiva de género. Col. Estudios 145 UAM 2: 233-256.

Price, T. D.; Knipper, C.; Grupe, G. y Smrcka, V. 2004: "Strontium Isotopes and Prehistoric Human Migration: The Bell Beaker Period in Central Europe". European Journal of Archaeology 7: 9-40.

Quesada, F. 2011: "Au-delà du guerrier: signification et fonction de l'armement dans les tombes féminines et d'inmatures dans la Péninsule Ibérique au second âge du Fer". En L. Baray, M. Honegger y M.H. Dias-Meirinho (ed.): L'armement et l'image du guerrier dans les sociétés anciennes. Éditions Universitaires de Dijon: 337-354.

Quesada, F. 2012: "Mujeres, amazonas, tumbas y armas: una aproximación transcultural". En L. Prados (ed.): La Arqueología funeraria desde una perspectiva de género. Col. Estudios 145, Universidad Autónoma de Madrid 2. Madrid: 317-364.

Riaño, J. F.; Rada y Delgado, J. de D. y Catalina García J. 1894: "Hallazgo prehistórico en Ciempozuelos". Boletín de la Real Academia de la Historia XXV: 436-450.

Ríos, P. y Liesau, C. 2011: Elementos de adorno, simbólicos y colorantes en contextos funerarios y singulares". En C. Blasco, C. Liesan y P. Ríos (eds.): Yacimientos calcolíticos con campaniforme de la Región de Madrid. Nuevos estudios. Patrimonio arqueológico de Madrid 9. Universidad Autónoma de Madrid. Madrid: 357-370.

Roca de Togores, C. 2011: "Estudio antropológico y paleopatológico de los enterramientos calcolíticos". En G. Pérez Jordá, J. Bernabeu, Y. Carrión, O. García Puchol, Ll. Molina y M. Gómez Puche (eds.): La Vital (Gandia, Valencia). Vida y muerte en la desembocadura del Serpis durante el III y el I milenio a. C. Servicio de Investigación Prehistórica del Museo de Prehistoria de Valencia, Serie de Trabajos Varios, 113. Valencia: 151-155.

Rojo Guerra, M.; Garrido Pena, R. y García-Martínez de Lagrán, I. 2005a (ed.): El Campaniforme en la Península Ibérica y su contexto europeo. Universidad de Valladolid y Junta de Castilla y León. Varona. Salamanca.

Rojo, M.; Kunst, M.; Garrido, R.; García, I. y Morán, G. 2005b: Un desafio a la eternidad. Tumbas monumentales del Valle de Ambrona (Soria, España). Memorias Arqueología en Castilla y León 14, Junta de Castilla y León. Valladolid.

Rojo Guerra, M.; Garrido Pena, R.; García-Martínez de Lagrán I.; Treserras, J. J. y Matamala, J. C. 2006:
"Beer and Bell Beakers: Drinking Rituals in Copper Age Inner Iberia". Proceedings of the Prehistoric Society 72: 243-265.

Salanova, L. 2011: “Chronologie et facteurs d'évolution des sépultures individuelles campaniformes dans le Nord de la France". En L. Salanova y Y. Tchérémissinoff (eds.): Les sépultures individuelles campaniformes en France. Gallia Préhistoire XLI ${ }^{\mathrm{e}}$ Supplément. París: 125-142.

Sampedro, C. y Liesau, C. 1998: "Los restos antropológicos". En C. Blasco, J. Baena y C. Liesau. La Prehistoria madrileña en el Gabinete de Antigüedades de la Real Academia de la Historia. Patrimonio Arqueológico del Bajo Jarama 3, Universidad Autónoma de Madrid. Madrid: 34-55.

Sanahuja, E. 2007: “¿Armas o herramientas prehistóricas? El ejemplo del mundo argárico". Complutum 18: $195-200$

Sánchez, M. 2006: "Maternidad y Prehistoria: prácticas de reproducción, relación y socialización. En Las mujeres en la Prehistoria. Diputación Provincial de Valencia, Museo Arqueológico de Valencia. Valencia: $119-137$.

Schubart, H. 2012: Die Gräber von Fuente Álamo. Madrider Beiträge 32, Reichert Verlag, Wiesbaden.

Siret, E. y Siret, L. 1890: Las Primeras Edades del Metal en el Sudoeste de España. Barcelona.

Strahm, C. 2004: "Le phénomène campaniforme et les composantes autochtones non campaniformes". Bulletin de la Société Préhistorique Française 101, 2: 201-206.

Thomas, J. 2005: "Ceremonies of the Horseman? Megalithic tombs to Beaker burials in Prehistoric Europe". En M. Rojo, R. Garrido e I. Martínez (eds.): El campaniforme en la Península Ibérica y su contexto europeo. Universidad de Valladolid. Valladolid: 123-135.

Trancho, G. y Robledo, B. 2011: "Reconstrucción paleonutricional de la población del Camino de las Yeseras". En C. Blasco, C. Liesau y P. Ríos (eds.): Yacimientos calcolíticos con campaniforme de la Región de Madrid. Nuevos estudios. Patrimonio arqueológico de Madrid 9, Universidad Autónoma de Madrid. Madrid: 133-154.

Vega, J.; Blasco, C.; Liesau, C.; Ríos, P.; Blanco, J. F.; Menduiña, R.; Aliaga, R.; Moreno, E.; Herrera T.; Petri, A. y Gómez, J. L. 2010: "La singular dualidad de enterramientos en el poblado de silos calcolítico de Camino de las Yeseras (San Fernando de Henares, Madrid)". En J. Fernández Eraso y J. A. Mujika Alustiza (eds.): Actas del Congreso Internacional sobre Megalitismo y otras manifestaciones funerarias contemporáneas en su contexto social, económico y cultural (Beasain. Idiazabal, Guipúzcoa 2007). Munibe. Suplemento 32. San Sebastián: 648-663. 